\title{
UNA CARTOGRAFÍA DEL TACTO: LA POÉTICA DEL INSTRUMENTO EN JOSÉ LUIS TORÁ (Madrid, 1966) ${ }^{1}$
}

\author{
A CARTOGRAPHY OF TOUCH: \\ POETICS OF THE INSTRUMENT IN JOSÉ LUIS TORÁ (Madrid, 1966)
}

\author{
Alejandro Morán Artaiz \\ Universidad Complutense de Madrid \\ amartaiz@gmail.com \\ ORCID ID: 0000-0002-8779-2703
}

\section{Resumen}

El presente artículo constituye una aproximación desde un punto de vista estético al trabajo con el instrumento musical que realiza en su obra el compositor español José Luis Torá (Madrid, 1966). En el contexto de su poética, el instrumento se entiende como un cuerpo sonoro, físico, provisto siempre de posibilidades acústicas no actualizadas. Además, se reconoce en él la existencia de una historia o "memoria" que contribuye a cargar de sentido, de antemano, las acciones instrumentales. El artista, partiendo de posicionamientos teóricos afines a los de quien fuera su maestro, Helmut Lachenmann, (y de otras influencias musicales, filosóficas y artísticas), se plantea la necesidad de una labor crítica que permita sacar a la luz nuevas relaciones acústicas en el instrumento en el proceso de creación musical. A lo largo de estas páginas se estudian las implicaciones filosóficas de dicha concepción del instrumento, enmarcándolas en la poética personal de Torá, y se analiza su huella en la escritura musical del autor a través de algunos ejemplos tomados de, entre otras obras, wq.132 à creux perdu (2017), Kaspar Hauser Lied (1993) e in der bruchlosen Ferne, dans le crevasse du temps (2001).

\section{Palabras clave}

José Luis Torá (1966-), música contemporánea, estética, instrumento musical, cuerpo sonoro, memoria, Kaspar Hauser Lied (1993), in der bruchlosen Ferne, dans le crevasse du temps (2001).

\begin{abstract}
This article presents an aesthetic approach to compositional process with the musical instrument developed by the Spanish composer José Luis Torá (Madrid, 1966). In the context of Tora's personal poetics, the instrument is conceived as a physical, sounding body, always capable of acoustic possibilities that have not been actualised yet. The artist recognizes in the instrument a historical dimension, or 'memory', which confers beforehand meaning to instrumental actions. Based on theoretical positions close to those of his former teacher Helmut Lachenmann, (and also influenced by other musical, philosophical and artistic figures), Torá defends the necessity of a critical and reflexive effort in the compositional process in order to bring out new acoustic relations inside the instrument. In the following pages, the philosophical implications of this vision of the instrument are studied and contextualised within Torá's personal poetics, analysing its traces in musical works such as wq.132 à creux perdu (2017), Kaspar Hauser Lied (1993) and in der bruchlosen Ferne, dans le crevasse du temps (2001).
\end{abstract}

\section{Keywords}

José Luis Torá (1966-), contemporary music, aesthetics, musical instrument, sounding body, memory, Kaspar Hauser Lied (1993), in der bruchlosen Ferne, dans le crevasse du temps (2001).

${ }^{1}$ Por la presente investigación sobre el compositor madrileño José Luis Torá, el autor recibió en 2019 una Mención de Honor en el Premio Otto Mayer-Serra, promovido por el Center for Iberian and Latin American Music (CILAM) de la University of California, Riverside. 


\section{INTRODUCCIÓN}

Antes de la existencia de los satélites artificiales, los métodos para la elaboración de representaciones cartográficas carecían de algo así como una mirada "desde arriba", un contemplar omnisciente que lo abarcase y distinguiese todo en un golpe de vista. Al contrario, los cartógrafos se veían obligados a recurrir a vías como la observación directa y el cálculo, además de la consulta de fuentes. Se trataba más bien, pues, de un punto de vista "desde abajo": los exploradores reconocían físicamente el espacio, reconstruyéndolo en cierto modo a partir de su propio camino.

De forma semejante, la expresión "cartografía del tacto" hace referencia a una exploración detenida de la mano que escribe, del gesto creativo que deja - por medio de la inscripción en el papel y de cada uno de los acontecimientos sonoros en los que esta se actualizauna huella sonora y poética. ${ }^{2}$ Así, el término "cartografía" no debe entenderse en el sentido de las técnicas de mapping empleadas hoy en día en la investigación musicológica, sino metafóricamente, como reconstrucción interpretativa de la realidad, ${ }^{3}$ la cual se conoce a través de una experiencia directa que renuncia a todo dominio a priori de la totalidad. Por otro lado, el "tacto" no es aquí sino otra imagen: la de esa mano sensible que tienta la realidad física que se le ofrece, oponiéndose, así, a un escudriñar clínico y - pretendidamente- objetivo, que reemplaza por un palpar sintiente y reflexivo.

Es esta idea, la de "cartografiar el tacto", la que se pretende llevar a cabo en este artículo, aplicándola a la poética del compositor José Luis Torá (Madrid, 1966);

\footnotetext{
2 “Actualización" se entiende como llevarse-a-la-presencia de una "virtualidad". Ambos conceptos proceden de la filosofía de Gilles Deleuze (1925-1995). En este contexto, lo virtual no se opone a lo real: la virtualidad conforma un espacio de posibilidad susceptible de devenir (llegar a ser) una posibilidad actualizada.

3 "Interpretativa" no quiere decir "subjetiva". Los mapas interpretan la realidad, a veces desde puntos de vista muy diferentes, pero ello no significa que todos los mapas posibles sean igualmente válidos.

4 Torá realizó sus estudios en el Real Conservatorio Superior de Música de Madrid, mientras recibía clases de compositores como Juan Carlos Martínez Fontana (n. 1962) o Mauricio Sotelo (n. 1961). Además, durante este periodo, tomó parte en cursos con, entre otros, Luis de Pablo (n. 1930), Tristan Murail (n. 1947), Salvatore Sciarrino (n. 1947) y Brian Ferneyhough (n.
}

me centraré en su labor creativa con el instrumento que implica una toma de postura estética respecto al mismo. ${ }^{5}$ Una peculiaridad de esta elección consiste en que, como veremos, el propio concepto de "cartografía del tacto" podría utilizarse para caracterizar algunos rasgos esenciales del trabajo compositivo de Torá. De este modo, el tacto se vuelve tanto el médium como el objeto de nuestra cartografía, en la medida en que ambas nociones - cartografía y tacto - se implican mutuamente en el seno de un espacio poético. Los motivos para la realización de esta investigación, entonces, no radican tanto en la carrera profesional de Torá o en la difusión de su música cuanto en la singularidad de su poética y su peso intelectual y creativo. A este respecto, deberá tenerse en cuenta no solo la relevancia de sus modelos - musicales, pero también filosóficos y artísticos-, sino el carácter personal que, ante todos ellos, adquieren sus planteamientos.

Nuestro objetivo último es realizar una cierta síntesis, un "mapa" que asista nuestra comprensión de la poética instrumental de Torá. Para tal fin se atenderá, por una parte, al proceso de reflexión existente en el trabajo de

1943), asistiendo también a los Internationale Ferienkurse de Darmstadt. Posteriormente, en Stuttgart (1995-1998), llevó a cabo estudios de posgrado con Helmut Lachenmann (n. 1935), al tiempo que trabajaba con Rainer Wehinger en el laboratorio de música electroacústica. Más tarde (1998-1999) se trasladó a Freiburg (Alemania), donde asistió a seminarios con Mathias Spahlinger (n. 1944). Su producción, hasta el día de hoy, incluye composiciones para solo, cámara, ensemble y coro. Su música se ha escuchado en festivales nacionales e internacionales como: Wittener Tage für neue Kammermusik (Witten), Tage für neue Musik (Zürich), Festival Smash (Salamanca), ULTIMA Festival (Oslo), SOUND Festival (Aberdeen), Internationale Ferienkurse (Darmstadt), IRTIJAL (Beirut), Festival Internacional de Música de Alicante, Foro de Nueva Música Ciudad de México y Visiones sonoras (Morelia), entre otros. Los datos biográficos incluidos en esta reseña proceden fundamentalmente de la página web de Torá (https://joseluistora.com/bio/bioesp) y de conversaciones sostenidas con el autor.

5 "Poética" se utiliza en este artículo en un sentido similar a "estética", esto es, como reflexión filosófica sobre el arte. La preferencia por "poética" se debe solo a las connotaciones "poyéticas" de su etimología (del griego poiesis: construcción, creación, composición), más adecuadas a la naturaleza del objeto de estudio, frente a las "estésicas" de la palabra "estética" (de aisthesis: sensación, percepción, conciencia). Véase José M. Pabón, Diccionario bilingüe Griego clásico-Español (Barcelona: Vox, 2017), pp. 17 y 487. 
Torá y a las implicaciones teóricas de sus posicionamientos. Por otra parte, se realizará un acercamiento a la obra de este compositor con el fin de analizar de qué modo todo ello se manifiesta en el proceso de creación.

En este trabajo convergen aspectos de corte filosófico y musicológico que lo dotan de una naturaleza interdisciplinar. Así pues, organizaremos nuestra exposición en tres partes. En una primera sección, someteremos a examen la concepción teórica del instrumento planteada por Torá, partiendo de su sintética definición: un cuerpo sonoro provisto de memoria. Desde la perspectiva de nuestro marco teórico, trataremos de comprender el sentido de estas ideas, así como sus implicaciones de cara a una poética del instrumento. En una segunda sección, encuadraremos la noción toraniana del instrumento en el conjunto de su poética. Con esta meta, abordaremos brevemente algunos de sus aspectos más relevantes, como su visión de la composición, el trabajo con modelos no-musicales e ideas clave como la traducción, la autodesaparición y la autolimitación. En la tercera sección, por último, nos aproximaremos a su obra para observar, por un lado, cómo los aspectos teóricos atendidos se manifiestan en formas específicas de trabajo creativo con el instrumento musical; y, por otro lado, de qué manera ello acarrea un impacto en el resultado escritural y sonoro de las obras. Dado el formato reducido de este texto, nos limitaremos a ofrecer algunos ejemplos en los que se reflejen con claridad algunos de los principales aspectos atendidos en los apartados precedentes.

La falta de estudios musicológicos previos sobre Torá nos fuerza a buscar otra clase de fuentes para nuestro trabajo. Por supuesto, al tratarse de un autor vivo, disponemos de información directa: la información de su portal web (incluyendo sus comentarios a sus obras), sus intervenciones en coloquios, conferencias y clases, bocetos y materiales de trabajo, así como conversaciones personales. No obstante, debemos evitar, como aconseja Jonathan Cross, convertir la palabra del autor en un discurso de autoridad que anule otras posibles visiones de su obra. ${ }^{6}$ En este sentido, la verdad del arte se encuentra ligada a

\footnotetext{
${ }^{6}$ Jonathan Cross, "Writing about Living Composers: Questions, Problems, Contexts", en Jonathan Cross, Jonathan Harvey, Helmut Lachenmann, Albrecht Wellmer y Richard Klein, Identity and Difference. Essays on Music, Language and Time, Collected Writings of the Orpheus Institute (Leuven: Leuven University Press, 2004, pp. 9-42, especialmente pp. 9-11.
}

una interpretación. La obra, siguiendo a Roland Barthes, aparece como un texto compuesto por una pluralidad de hebras entretejidas: no se trata tanto de "descifrar" cuanto de "desenredar" una madeja de hilos en la que caben más de una perspectiva.? Así, según Hans Georg Gadamer, "la comprensión no es nunca un comportamiento solo reproductivo, sino que es a su vez siempre productivo", lo cual se lleva a cabo dentro de un determinado "horizonte hermenéutico positivo". ${ }^{8}$ Nuestra labor consistirá en iluminar el objeto de estudio de tal modo que este se muestre en una luz adecuada, aunque también crítica. Para ello se hace necesario definir un marco teórico que proporcione las coordenadas idóneas para una aproximación eficaz a la poética de Torá. Tales coordenadas se han planteado partiendo de los referentes intelectuales del propio autor, que constituyen tres grupos diferenciados.

Un primer grupo de referentes intelectuales de Torá está constituido por compositores como Luigi Nono y Karlheinz Stockhausen, a los que pueden sumarse otras figuras relevantes en su formación, como Mathias Spahlinger. ${ }^{9}$ La figura más destacable es quizás la de Helmut Lachenmann, por el alcance y profundidad de su influencia en la música de Torá y a pesar de la distancia que separa sus respectivas poéticas. Debe señalarse que, junto a su producción creativa, Lachenmann es autor de una notable obra teórica. Asimismo, su obra ha sido objeto de una larga serie de investigaciones en los últimos años, muchas de las cuales se han mostrado útiles en nuestro acercamiento a la música de Torá. Entre las más relevantes, citaremos a lo largo del presente estudio las de Abigail Headlicote (2003), Paulo de Assis (2011), Markus Neuwirth (2008), Samuel Wilson (2013) y Annette Bro$\sin (2015)$.

Una segunda serie de figuras de referencia para Torá procede de la filosofía. Conforman dicho grupo nombres como Theodor Adorno, Maurice Merleau-Ponty, Gilles Deleuze, Roland Barthes, Michel Foucault, Walter Benja-

${ }^{7}$ Roland Barthes, El susurro del lenguaje (Barcelona: Paidós, 1987: 70).

${ }^{8}$ Hans G. Gadamer, Verdad y método [I] (Madrid: Trotta, 2012), pp. 366, 337-341.

9 Durante una conversación sostenida el 17 de noviembre de 2017, Torá añadía como referente la música tradicional japonesa, fascinación que se vería reflejada, a juicio del propio autor, en la "ritualización del acto de escucha" en su discurso musical. No obstante, esta posible influencia no será valorada en el marco del presente trabajo. 
min y Martin Heidegger. Podríamos citar también a Hans G. Gadamer, Albrecht Wellmer o Jacques Derrida, cuya pertinencia aquí se mostrará a lo largo de este estudio.

Un último grupo de referentes de Torá está formado por poetas como Paul Celan, José M. Ullán y Arnaut Daniel, y artistas plásticos como Anish Kapoor y Alberto Giacometti. Su importancia en la poética toraniana no ha de ser subestimada, en la medida en que unos y otros, más que como "fuentes de inspiración", aparecen aquí en calidad de productores de ideas y modelos creativos que Torá se esforzará por hacer devenir musicales y, a través de ese proceso, devenir él mismo poeta y artista plástico. ${ }^{10}$

\section{EL CARÁCTER DUAL DEL INSTRUMENTO MUSICAL: CUERPO Y MEMORIA}

En un comentario escrito por Torá a su pieza in der bruchlosen Ferne, dans le crevasse du temps (2001), para flauta, clarinete, percusión, violín y violonchelo, el compositor arrojaba la siguiente definición: "por un lado, el instrumento es considerado como cuerpo sonoro, como espacio acústico de relaciones latentes; por otro, como portador de historia, de una tradición interpretativa". Esta noción dual desempeña un papel fundamental en su poética del instrumento. ${ }^{11}$ ¿Qué significa esta idea? Comen-

10 Véase Gilles Deleuze y Félix Guattari, Mil mesetas. Capitalismo y esquizofrenia (Valencia: Pre-Textos, 2015), p. 303: "ningún arte es imitativo [...]: supongamos que un pintor representa un pájaro; de hecho, se trata de un devenir-pájaro que sólo puede realizarse en la medida en que el pájaro está a su vez deviniendo otra cosa [...] sólo se imita si se falla, cuando se falla. El pintor o el músico no imitan al animal, son ellos los que devienen-animal, al mismo tiempo que el animal deviene lo que ellos querían".

11 Además, según afirmaba Torá en una conversación del 11 de noviembre de 2017, dicha concepción se habría mantenido constante a lo largo de su trayectoria. Ello se refleja en las distintas notas que escribe sobre sus obras, al menos desde in der bruchlosen Ferne.... Así, un año después, en d'un trait qui figure et défigure (2002): “...la corporalidad de los instrumentos, su consideración como cuerpos sonoros que poseen una acústica y una historia propias, que tienen su propia poética y no admiten abstracciones". Y de forma más reciente, en wq.132 à creux perdu (2017): “...el cuerpo físico, frío, formado acústica e históricamente, del saxofón tenor". No obstante, en las primeras obras de su catálogo, como Kaspar Hauser Lied (1993) o a ras de los albores más tempranos (1996-1997), el foco parece situarse primordialmente en el aspecto corporal del instrumento. Véase, por zaremos por estudiar la definición expuesta e indagar sobre sus implicaciones teóricas, atendiendo por separado cada uno de los dos aspectos.

\subsection{El instrumento como cuerpo sonoro}

Para empezar, el instrumento es comprendido como "cuerpo". Sin embargo, ha de aclararse en qué sentido debe entenderse esto. ¿Es este "cuerpo" equivalente al "objeto", o al "cuerpo" de la mecánica clásica? La definición de Torá apunta en una dirección distinta. El instrumento es aquí un "otro" con el que se interactúa, dotado de un potencial sonoro que se actualiza por medio de la interacción física. Esta, mientras tanto, se concibe como una exploración consciente pero receptiva: se trata de escuchar "lo que el instrumento nos ofrece", aunque para ello el compositor haya de interpelarlo - lo que ya nunca es neutro.$-{ }^{12}$

En efecto, toda escucha posee una orientación que condiciona la exploración. Pero este sesgo, al igual que en Gadamer, se convierte para Torá en un principio positivo, un punto de partida afirmativo en el trabajo de creación. Pero esta receptividad y disposición de apertura al ser-del-otro colisiona radicalmente con toda visión del instrumento como "objeto", en cuanto mera herramienta. Según Merleau-Ponty, el objeto

no admite entre sus partes, o entre él y los demás objetos, más que relaciones exteriores y mecánicas, ora en el sentido estricto de un movimiento recibido y transmitido, ora en el sentido lato de una relación de función a variable. ${ }^{13}$

Un ente, al ser pensado como útil, solo establece este tipo de relaciones. Así, en el destornillador, tanto su estructura física (la conjunción de mango, cuerpo, y punta) como la acción humana que recibe se orientan a la consecución de un fin concreto: introducir y extraer tornillos. Esta relación del destornillador con el tornillo, el

ejemplo, Torá, Notas a "de una estela incierta (-Aschenlid)" (1996-1997, rev. 1999): “ “...espacio en el cual el sonido, su corporalidad instrumental, impone como eje vertical sus propias condiciones, convirtiéndose él mismo en un espacio de posibilidades".

12 La expresión "lo que el instrumento nos ofrece" fue utilizada por Torá el 19 de diciembre de 2015, en el marco de una clase ofrecida en el Centro Superior Katharina Gurska de Madrid (desde ahora CSKG).

13 Maurice Merleau-Ponty, Fenomenología de la percepción (Buenos Aires: Planeta, 1993), p. 92. 
agujero y el usuario es, en general, la única que el destornillador establece con el mundo. No obstante, cabe preguntarse si esta utilidad bastaría para "explicar" el destornillador. Es decir, si ello agota su potencial o, más bien, lo confina a un lugar configurado como habitus. Al relegarlo a una función estereotipada, el útil queda vinculado al ámbito del man (se) heideggeriano, al dominio de lo familiar y lo impersonal: se hace, se dice, se comenta.... Uno sabe qué es un destornillador si conoce esas propiedades que lo habilitan como útil, y lo sabe manejar si sabe emplearlo diestramente para $s u$ fin. ¿Qué ocurre ahora si aplicamos esto al instrumento musical? En este caso, uno sabe cómo suena una viola si sabe cómo se hace sonar y, asimismo, uno sabe tocar la viola si puede tocarla de la manera en que esta se toca. Esto plantea varias cuestiones en relación con la identidad y la memoria ligadas al instrumento, a las que retornaremos en el apartado 1.2.

Sin embargo, Merleau-Ponty daba cuenta del fracaso del intento de reducir la experiencia del cuerpo a la fisiología mecanicista o a la psicología.${ }^{14}$ Frente a esto, el pensador belga introducía la idea de un "horizonte fenomenológico" inherente a la experiencia. Este sería precursor, en cierto modo, del "horizonte hermenéutico" de Gadamer, tal y como este mismo parece apuntar. ${ }^{15} \mathrm{El}$ cuerpo que analiza Merleau-Ponty es el cuerpo humano y, en concreto, el propio cuerpo. No obstante, en su descripción de la experiencia de los "otros" cuerpos puede verse un germen del "cuerpo sonoro" toraniano. Este implica una reivindicación del instrumento musical como ser-ensí más allá de su funcionalidad, cuerpo-otro con el que se dialoga en el contexto de la praxis musical, pero también de su palpabilidad: "la corporalidad de los instrumentos, su consideración como cuerpos sonoros". ${ }^{16}$ Además, como señala Samuel Wilson, el carácter central que en Merleau-Ponty adquiere el cuerpo en la experiencia del mundo acarrea importantes consecuencias sobre la manera de pensar no solo el propio instrumento, sino también la dualidad intérprete-instrumento. ${ }^{17}$

El conocimiento del mundo no es, pues, construido de forma a priori por la mente, sino a través del cuerpo.

\footnotetext{
14 Merleau-Ponty, Fenomenología de la percepción, p. 99.

15 Gadamer, Verdad y método [I], p. 309.

16 José Luis Torá, Notas a "d'un trait qui figure et défigure" (2002).

17 Samuel Wilson, "Building an Instrument, Building an Instrumentalist: Helmut Lachenmann's Serynade", Contemporary Music Review, 32/5 (2013), p. 428.
}

Así, según Michael Serres: "el origen del conocimiento reside en el cuerpo [...]. No conocemos nada ni a nadie hasta que el cuerpo adopta su forma, apariencia, movimiento, habitus, hasta que el cuerpo se une en la danza con su conducta". ${ }^{18}$ Es la idea de la embodied mind (mente encarnada) que rompe con el dualismo tradicional mente-cuerpo. Merlau-Ponty, en este sentido, concibe la conciencia como conciencia encarnada, no escindida del cuerpo o del mundo. A este respecto, el filósofo saca a colación el caso de la amputación: ¿cómo condiciona esta la experiencia del cuerpo? ¿Cómo cambia la percepción respecto a la persona sin brazos o al ciego? De este modo, la percepción se convierte en un hecho mediado, tanto por las condiciones que plantea el cuerpo como por el propio conocimiento. La idea de una mirada objetiva se torna una ilusión: la percepción es parcial, está ligada a una cierta perspectiva. Torá recogía esta idea, al afirmar: "podemos ver tan solo una parte de la totalidad, la cual sólo se alcanza a través de una reconstrucción e interpretación de lo dado. No ves una cabeza esférica: la supones". ${ }^{19}$

Otro aspecto de esta mente encarnada, in-corporada, es la cuestión del "sintiente sentido": mi mano, al tocar mi mano, toca y es tocada. Pero también en cierto modo, proseguía Torá, "al tocar un violín, el violín me toca a mí". Esto constituye un rechazo de la dicotomía entre sujeto y objeto: al pensar el violín como objeto, descarto la idea de que este pueda tocarme, pero al pensarlo como cuerpo, "se tambalean las nociones de «interior»y «exterior»". La dualidad intérprete-instrumento, empero, también se ve afectada, volviéndose interdependiente: el instrumento no puede ser pensado al margen de la acción del intérprete. Como subraya Wilson, instrumento e intérprete son (re)construidos uno en relación con el otro. ${ }^{20}$

¿Qué decir de la expresión "espacio acústico de relaciones latentes"? El cuerpo es una realidad sensible y

${ }_{18}$ Michael Serres, Variations on the Body (Minneapolis: Univocal, 2011), pp. 70-71: "The origin of knowledge resides in the body [...]. We don't know anyone or anything until the body takes on its form, its appearance, its movement, its habitus, until the body joins in a dance with its demeanor"; citado por Annette Brosin, "Musical Memory, Cultural Memory, and Digital Technologies: Perspectives and Analytical Approaches", tesis doctoral, University of Victoria [Canadá], 2015, p. 186.

19 Afirmado durante la citada clase del 19 de diciembre de 2015 [véase nota 12 ].

20 Wilson, "Building an Instrument, Building an Instrumentalist”, p. 425. 
corpórea, abierta, no cerrada. Es abierta porque es indisponible en su totalidad, no puede dominarse por completo puesto que siempre caben nuevas lecturas; su potencial experiencial excede el marco del man y lo familiar. Así, al trascender la funcionalidad objetual y emerger como "cuerpo", el instrumento se convierte en espacio hermenéutico. Las "relaciones latentes" tienen que ver con esa virtualidad no actualizada. La imagen heideggeriana de los "caminos de bosque" puede ser ilustrativa a este respecto:

En el bosque hay caminos (Wege), por lo general medio ocultos por la maleza, que cesan bruscamente en lo no hollado. Es a estos caminos a los que se llama Holzwege (caminos de bosque, caminos que se pierden en el bosque). Cada uno de ellos sigue un trazado diferente, pero siempre dentro del mismo bosque. ${ }^{21}$

Estos caminos, interrumpidos en lo desconocido, pueden asociarse con las "relaciones latentes". Lo latente se halla en esa maleza virgen, ignota para los mapas y no marcada por el pie humano. Es aquello que está oculto y solo se revela al paso del explorador inquieto: aquellas propiedades acústicas contenidas en el instrumento que el compositor permite que emerjan a la presencia a través del trabajo creativo. Su emergencia tiene que ver aquí con lo que Lachenmann denomina instrumental defamiliarisation: la concepción del sonido como algo palpable, un fenómeno natural, evocando así modos de escucha antes excluidos..$^{22} \mathrm{La}$ "pérdida de carácter familiar" supone ante todo la persecución de un extrañamiento frente a lo conocido, aspirando de esta manera a romper la alienación del hábito. ${ }^{23}$ Este redescubrimiento del elemento corporal del

${ }^{21}$ Martin Heidegger, Caminos de bosque (Madrid: Alianza, 2010), p. 9.

${ }^{22}$ Helmut Lachenmann, "Philosophy of Composition -Is there such a thing?", en Jonathan Cross, Jonathan Harvey, Helmut Lachenmann, Albrecht Wellmer y Richard Klein, Identity and Difference. Essays on Music, Language and Time. Collected Writings of the Orpheus Institute (Leuven: Leuven University Press, 2004), pp. 55-70, especialmente pp. 64-66.

23 Encontramos implicada aquí la clásica dicotomía entre los conceptos de Verfremdung y Entfremdung. Véase Lachenmann, "Cuatro aspectos fundamentales de la escucha musical" [1979, trad. de Alberto Bernal], consultado el 20 de agosto de 2020 de http://www.tallersonoro.com/anterioresES/07/Articulo2.htm, nota 7: “...si bien ambos términos comparten una raíz común (fremd: extraño, no habitual, foráneo), en este caso precisamen- sonido, con el consiguiente énfasis en la producción sonora (acción física sobre el instrumento), conforma la base de la noción de musique concrète instrumentale:

El término hace alusión al de musique concrète acuñado por Pierre Schaeffer. En lugar de emplear de forma instrumental acciones mecánicas cotidianas [...], lo planteo desde la comprensión del sonido instrumental como información sobre su producción [...] a través de la iluminación de los sonidos instrumentales como procesos mecánicos. ${ }^{24}$

Debe recordarse que Lachenmann desarrolla sus planteamientos estéticos desde una postura crítica cuyo principal interlocutor es la vanguardia de posguerra. Es así fácil de comprender el sentido de este redescubrimiento, de su deseo de reflexionar sobre lo que se sitúa detrás de las "categorías", de escapar de la prisión del puntillismo y la degradación del sonido a mera información objetiva. ${ }^{25}$ El serialismo había tratado de "parametrizar" el sonido, de domesticarlo en cierto modo a través de la matemática. Por esta vía, algunos compositores habrían logrado provocar la pérdida de carácter familiar de las relaciones sonoras tal como se presentaban a la escucha. Pero esto convivía con la supervivencia de hábitos en aspectos

te juegan papeles diferentes, casi contrarios. El sentido con el que [Lachenmann] utiliza aquí el término 'Verfremdung' ('distanciamiento') nos remite directamente a Bertolt Brecht, para el que la Verfremdung [...] consistía en la acción de presentar elementos familiares o habituales al espectador a través de una nueva luz, bajo una nueva forma, con el fin de hacer visibles y evidentes las contradicciones de la realidad [...]. Por el contrario, el vocablo 'Entfremdung' ('enajenación') ilustra un estado ya enajenado, la pérdida o distanciación definitiva del Otro, el ya no tener Otro. Para Brecht, al igual que para Lachenmann, constituye lo primero (Verfremdung) un acto de superación de lo segundo. Se trata de un 'distanciamiento' utilizado como negación de la negación [...]; es, por tanto, una herramienta para neutralizar y deshacer la enajenación".

${ }^{24}$ Lachenmann [1996], citado en Abigail Headlicote, Liberating Sounds: Philosophical Perspectives on the Music and Writings of Helmut Lachenmann (Durham: Durham University, 2003), p. 54. "The term refers to that of Pierre Schaeffer's musique concrète. Instead of instrumentally using mechanical everyday actions [...] I go about it by understanding the instrumental sound as information about its production [...] by illuminating instrumental sounds as mechanical processes".

${ }^{25}$ Lachenmann, "Philosophy of Composition -Is there such a thing?", pp. 64-65. 
como la producción sonora, además de intensificar la alienación del sonido a través de su in-materialización y des-corporalización, cuya máxima expresión se encontraría en la música electrónica. Frente a esta postura, Lachenmann tratará de recuperar la dimensión física y corpórea del sonido. Sin embargo, Lachenmann ya había tenido que hacer frente a resistencias que asociaban su propuesta con otras actitudes, como las que él mismo asocia con un "manierismo del color" y un "neo-surrealismo" ${ }^{26}$ A este último, basado en lo grotesco y el humor (y cuyos rasgos detecta en Ligeti y Kagel), Lachenmann atribuye una deriva "pseudorradical" que debilitaría su carga crítica en beneficio del entretenimiento o la extravagancia: una vanguardia "simpática" en la que la pérdida de carácter familiar, aunque intensa, no se toma del todo en serio.$^{27}$ ¿De qué manera trata Lachenmann de distanciarse de esto?

Nótese que, en su definición de instrumento, Torá habla de "relaciones" y no de "sonidos", al igual que Heidegger escribía "caminos" y no "árboles". Esta búsqueda de lo no hollado no consiste, pues, en el mero afán de coleccionar sonidos nuevos, como si nuestra expedición por el bosque se orientase tan solo a recoger raras variedades de champiñones y plantas aromáticas. Esta actitud, incluso, sería ridiculizada y descrita como "botánica" por Lachenmann:

La riqueza de los nuevos sonidos no ha sido descubierta como un fin en sí mismo, sino para el propósito de sensibilizar nuestra capacidad de escucha en nuevos sentidos. Ciertamente, siempre hay nuevas técnicas instrumentales que descubrir y no hay necesidad de evitarlas. Pero los "sonidos nuevos" como tales no son lo esencial, sino un modo de escucha que constantemente ha de renovarse a sí mismo a través de la reflexión y mostrar igual eficacia al enfrentar sonidos tanto familiares como no familiares. ${ }^{28}$

${ }^{26}$ Lachenmann, "Philosophy of Composition -Is there such a thing?", p. 66.

${ }^{27}$ Lachenmann, Musik als existentielle Erfahrung (Wiesbaden: Breitopf \& Härtel, 1996), pp. 29-34.

${ }^{28}$ Lachenmann, "Philosophy of Composition -Is there such a thing?", pp. 66: "The wealth of new sounds had not been discovered as an end unto themselves, but rather for the sake of sensiting our listening capacity in new ways. Certainly, there are always new instrumental techniques to discover, there is no need to avoid them. But 'new sounds' as such are not the point; rather a mode of listening that constantly renews itself through
Con palabras semejantes nos hablaba Torá al hacer referencia a esta cuestión. Uno - decía - siempre puede encontrar sonidos nuevos. Pero el trabajo del artista consiste ante todo en dotar de nuevos sentidos a los ya conocidos, mediante la creación de contextos en los que lo familiar se escuche de una forma nueva. ${ }^{29}$

Por último, las características físicas del instrumento musical, en cuanto condicionantes de lo que este puede o no hacer (y cómo), no son pensadas aquí como "limitaciones", sino como apertura de posibilidades. Asumir los límites que marcan las propiedades acústicas del instrumento es una forma de aceptar su corporeidad y, también, -(in)directamente - , la del intérprete. No es de sorprender, por tanto, que tanto Torá como Lachenmann hayan centrado su trabajo en los instrumentos tradicionales frente a los medios electrónicos. Según Headlicote, "los dispositivos electrónicos pueden proporcionar una [gran] riqueza de posibilidades para la música «progresista», pero [...] fracasan al enfrentarse directamente a la tradición y la convención, la historicidad del material musical y sus asociaciones expresivas". ${ }^{30} \mathrm{O}$, como lo expresa el propio Lachenmann: "a causa de su vasta riqueza, el sonido electrónico es demasiado «seguro» - rápidamente se oxida para convertirse en un idilio exótico, surreal y expresionista $-" 31$

\subsection{El instrumento como portador de historia}

Las últimas apreciaciones apuntan a una nueva faceta del instrumento: su condición como "portador de historia". El instrumento no es un cuerpo estéticamente neutro; los sonidos que en él se producen poseen, en mayor o menor medida, una historia. Esto alcanza incluso a los sonidos "nuevos", que inevitablemente tienden a estable-

reflection, and which must show equal proficiency in dealing with familiar and unfamiliar sounds".

29 Afirmado en el marco de una clase individual el 25 de octubre de 2015 en el CSKG.

${ }^{30}$ Headlicote, Liberating sounds, p. 65: "Electroacoustic devices may provide a wealth of possibilities for 'progressive' music, but $[\ldots]$ they fail to engage directly with tradition and convention, with the historicity of musical material and its expressive associations".

31 Lachenmann, Musik als existentielle Erfahrung, p. 211: "For all of its vast wealth, electronic sound is too 'safe' - it quickly oxidizes to become an exotic, surreal, expressionistic idyll-". 
cer en nuestra mente asociaciones con otros ya escuchados. De este modo, dice Torá, los sonidos están “cargados", provistos de sentido a través de todas las relaciones en las que se han visto envueltos..$^{32}$ Pero también los mismos instrumentos se hallan cargados; como exponíamos antes, el sonido no se entiende como un fenómeno abstracto, sino encarnado en la experiencia de los cuerpos. ${ }^{33}$ Todo ello obliga al compositor a adoptar una determinada postura frente al instrumento, a no ser indiferente ante su historia. Así, reflexionar sobre el pasado mediante un "análisis clínico del material" se torna un momento central del trabajo creativo. ${ }^{34} \mathrm{O}$, como lo expresa la primera tesis de Lachenmann sobre la creación: "reflexionar sobre el medio" [über die Mittel nachdenken $]{ }^{35}$ Esto consiste, según el músico alemán, en sensibilizarse a las preconfiguraciones de la escucha y los recursos creativos, exponiéndose al riesgo y adquiriendo conciencia de la responsabilidad social del artista. ${ }^{36}$ Para tal fin, debe realizarse un diagnóstico adecuado de cuatro aspectos del material musical: "tonal", "sensorial", "estructural" y "existencial". ${ }^{37}$

En el aspecto sensorial [sinnlicher Aspekt], los materiales se perciben como estímulos corporales transmitidos mediante información física. Por su parte, el aspecto estructural [struktureller Aspekt] entiende el sonido como

32 Aquí Torá concuerda, una vez más, con Lachenmann: “El material musical no es un mero substrato dócil, a la espera de ser despertado por los compositores a la vida expresiva en cualquiera que sea el contexto, sino que, antes de que siquiera el compositor tenga la oportunidad de acercarse a él, está ya contextualizado y caracterizado expresivamente. Tales condiciones [...] tienen origen en la propia realidad, la cual nos ha conformado a nosotros mismos [...] a nuestra existencia y a nuestra conciencia". Véase Lachenmann, "Cuatro aspectos fundamentales de la escucha musical", p. 2.

${ }^{33} \mathrm{O}$, como lo expresaba Pierluigi Billone durante una clase ofrecida en el CSKG el 20 de febrero de 2016: "Sound is at the same time the reality of the sound and the reality (the practice) of the body $[\ldots]$ an interaction between an instrument and a human being" [el sonido es al mismo tiempo la realidad del sonido y la realidad (la práctica) del cuerpo (...) una interacción entre un instrumento y un ser humano].

${ }^{34}$ Paulo De Assis, "The conditions of creation and the haecceity of the music material: Philosophical-aesthetic convergences between Helmut Lachenmann and Gilles Deleuze", Filigrane, 13 (2011), p. 2.

35 Lachenmann, Musik als existentielle Erfahrung, p. 74.

36 Lachenmann, "Philosophy of Composition", p. 57.

37 Lachenmann, Musik als existentielle Erfahrung, p. 35. la articulación de sistemas y leyes en el tiempo. ${ }^{38}$ Los otros dos aspectos, tonal y existencial, se encuentran fuertemente ligados a la idea de memoria. Así, bajo el término "tonalidad" [Tonalität]

se engloba no solamente el total de nuestro complejo de experiencias con el aparato estético legado - con sus categorías de armonía, melodía y ritmo [...]-, sino también la praxis musical, instrumental o notacional, no siendo el material lo único que está preconfigurado tonalmente, sino estándolo también en la misma medida nuestra propia conciencia y comportamiento auditivo. ${ }^{39}$

Es decir, Lachenmann no se refiere solo a las relaciones armónicas en el lenguaje tonal, sino a la forma en que cualquier aspecto del sonido o de la percepción se encuentra moldeado por la tradición o se sitúa, al menos, en relación a ella. ${ }^{40}$ ¿Qué consecuencias tiene esto sobre el instrumento? Podemos pensar aquí en la técnica instrumental, que describe y prescribe modos específicos de acceso al instrumento, una manera de hacer decantada a través de la historia. A este respecto, como explica Wilson, un piano es un objeto que puede ser "sentido, palpado, tocado". Sin embargo, lejos de constituir una pura entidad física, una "pieza inerte de tecnología", el piano porta consigo una tradición interpretativa, desarrollada a través del repertorio, y que, inscrita en el instrumento, condiciona las relaciones entre el cuerpo de este y el del intérprete, así como la propia manera de escuchar y experimentar el instrumento. ${ }^{41}$

Lejos de ser un producto "natural", la técnica instrumental posee un componente de convención, de códigos compartidos, transmitidos de profesores a alumnos a través de la enseñanza y del repertorio. Así, al igual que en otras dimensiones de la "tonalidad" lachenmanniana, las transformaciones que un intérprete o compositor puede producir sobre la técnica de un instrumento se posicionan siempre respecto una tradición heredada. La "tonalidad", empero, no es algo absolutamente negativo. En innumerables casos la estandarización de la técnica hace viable la praxis musical. Pensemos, por ejemplo, en un

\footnotetext{
38 Lachenmann, "Philosophy of Composition", p. 58.

39 Lachenmann, "Cuatro aspectos fundamentales de la escucha musical", p. 2.

40 Lachenmann, "Philosophy of Composition", p. 58.

${ }^{41}$ Wilson, "Building an Instrument, Building an Instrumentalist”, pp. 426-427.
} 
tutti de cuerda de una orquesta tradicional, donde se requiere que las secciones toquen como un solo intérprete: movimientos del arco, vibrato, posiciones de la mano izquierda.... Todos estos elementos técnicos, en los que es instruido todo músico de cuerda y cuyo dominio se le exige, contribuyen a conformar una identidad del instrumento y del instrumentista en la que participan también otros elementos canónicos: repertorio, "escuelas", intérpretes prestigiosos, entre otros. Y, por supuesto, la identidad tiene también un lado negativo, excluyente. En este punto, el estándar técnico se muestra una vez más como habitus, dominio del man, "territorio", en términos deleuzianos: un camino pavimentado que habrá de ser confrontado críticamente por el compositor.

El último aspecto del material es denominado "existencial" [existentieller Aspekt] o "aura". Este último fue, en origen, un término acuñado por Benjamin para caracterizar la particular unicidad de ciertos objetos, entre los cuales se encontraban las obras de arte. Benjamin define el aura como "manifestación irrepetible de una lejanía, por lejana que esta pueda hallarse" ${ }^{42}$ Esto no representa otra cosa, según Jesús Aguirre, que "la formulación del valor cultural de la obra artística en categorías de percepción espacial-temporal". ${ }^{43}$ Así pues, según Torá, el aura benjaminiana constituye un nudo entre la simultaneidad (el espacio) y la sucesividad (el tiempo). El espacio se yergue como poder de la distancia, mientras se establece el tiempo como poder de la memoria. Un objeto aurático - cualquier objeto revestido con el hábito de lo "cultural" - adquiere de inmediato una distancia respecto al observador, por muy cerca que se encuentre físicamente de él. En el instrumento, el aura aparece como resistencia al rebajamiento de aquél a la condición de útil (no-aurática). En cuanto aurático, el instrumento adquiere la posibilidad de trascender el hechizo de lo dado. Esto es: "el objeto aurático ostenta el poder de «abrir los ojos», propio de lo poético". ${ }^{44}$

${ }^{42}$ Walter Benjamin, "La obra de arte en la época de su reproductibilidad técnica", en Obras [I.2] (Madrid: Abada, 2008), pp. 7-86, p. 16.

43 Jesús Aguirre, "Prólogo" a su traducción de Walter Benjamin, Discursos interrumpidos I (Buenos Aires: Taurus, 1989), p. 26.

${ }^{44}$ Expuesto por Torá durante la mencionada clase del 19 de diciembre de 2015. De esta forma, Torá tiende un puente entre ambas caras de la definición. Pero esto, a nuestro juicio, conlleva una seria implicación: ese "poder" solo se actualiza a través
El concepto de aura será revisitado por Adorno, identificándose entonces con el "espíritu": aquello que excede la configuración material y sonora de la obra, incluyendo su cualidad como objeto. Más adelante, en Lachenmann, adquirirá el valor de una significación mediante la que la música nos atañe existencialmente. ${ }^{45}$ En el contexto de la teoría lachenmanniana, si la "tonalidad" venía ligada al moldeamiento del material a través de la tradición, el aura vendría a ser la historia del material en cuanto a sus contextos extramusicales. ${ }^{46}$ Esto significa que la carga sedimentada por el pasado excede el ámbito específico de lo musical, incursionando en el terreno de las connotaciones y significaciones adquiridas, tanto en la memoria de los oyentes como en los mismos hábitos perceptivos de nuestra realidad sociocultural. ${ }^{47}$ En consecuencia, además de actuar como resistencia a su objetualización, el aura del instrumento posee una vertiente identitaria, ligada a una serie de resonancias extramusicales, relacionadas con rasgos como la procedencia de los instrumentos o los diversos usos recibidos.

Considérense, por ejemplo, las evocaciones que acuden a la mente de un oyente "occidental", de forma automática, al oír tañer una campana. Templo, espiritualidad, muerte.... Ello condiciona necesariamente la forma en que se escucha la campana; su solo sonido se encuentra de antemano cargado de significación. Otros ejemplos ilustrativos serían las asociaciones cinegéticas de la trompa, militares de la caja y meditativas de los cuencos tibetanos. En otros casos, quizás, el contenido del aura no es tan evidente. Sin embargo, todo instrumento posee sus propias atribuciones simbólicas, vinculadas a aspectos como su imagen social, su iconografía o sus roles en la praxis musical. Podemos recordar, en este sentido, el pa-

de un distanciamiento crítico. En consecuencia, la apertura al instrumento como cuerpo sonoro, la capacidad para mostrarlo en su inmediatez como ser-que-toca, estará en función de que logren romperse los hábitos perceptivos sedimentados a lo largo de la historia.

45 Albrecht Wellmer, "On Music and Language", en Jonathan Cross, Jonathan Harvey, Helmut Lachenmann, Albrecht Wellmer y Richard Klein, Identity and Difference. Essays on Music, Language and Time. Collected Writings of the Orpheus Institute (Leuven: Leuven University Press, 2004), pp. 71-132, p. 106.

46 Lachenmann, Musik als existentielle Erfahrung, pp. 3547.

47 Lachenmann, "Philosophy of Composition", p. 58. 
pel de las campanas en la Symphonie Fantastique de Berlioz o el de los cencerros en la Sinfonía n. ${ }^{\circ} 7$ de Mahler. La explotación del aura de los instrumentos se da asimismo a través de aspectos propiamente "tonales", como la imitación de elementos denominados — de forma elocuente - "idiomáticos": el rasgueo de la guitarra en el alla chitarra del violín, las imitaciones de "llamadas" de trompa, etc. ${ }^{48}$

Encontramos aquí una clara relación entre esta noción de aura y la de "tópico musical", cara a los estudios de semiótica musical. Como señala Rubén López-Cano, el tópico, aplicado en un principio por Leonard Ratner al análisis del repertorio del Clasicismo, es un "lugar común" que remite "intertextualmente a estilos, tipos o clases de músicas reconocibles por el escucha competente". ${ }^{49}$ Además, según argumentaría más adelante Raymond Monelle, el tópico emerge como resultado de un "proceso de convencionalización", a través del cual los signos musicales se convierten en "símbolos", (en sentido peirceano); pero esto implica, como comenta Óscar Hernández Salgar, que el tópico se encuentra en última instancia ligado a la "familiaridad", al hábito sedimentado..$^{50}$

De este modo, en Lachenmann, así como en Torá, el aura del instrumento se convertirá en un nuevo objeto de

48 Véase Mathias Spahlinger, "Realidad de la conciencia y realidad para la conciencia. Aspectos políticos de la música" [1992], traducción de Alberto Bernal; consultado el 23 de agosto de 2020 en http://docs.albertobernal.net/bernal_musica-y-realidad-2.html, p. 2: "el aura de los instrumentos; aquello que (por tradición) conllevan las instrumentaciones prominentes, los géneros, las formas... alusiones a estilos y sociolectos (con una intención folclórico-colorista, colonialista, o bien con el excelso propósito de ayudar a que los oprimidos sean oídos); procedimientos que transportan consigo mismos una asociación a su función original; emblemas abiertos o enmascarados de cualquier color político; reminiscencias de músicas que hayan adquirido un determinado significado a través de su utilización en determinados contextos".

49 Leonard G. Ratner, Classic Music: Expression, Form and Style (Nueva York: Schirmer Books, 1980); citado por Rubén López-Cano, "Entre el giro lingüístico y el guiño hermenéutico: tópicos y competencia en la semiótica musical actual”, Revista Cuicuilco, 9/25 (2002), p. 13.

${ }^{50}$ Raymond Monelle, The Sense of Music: Semiotic Essays (Princeton: Princeton University Press, 2000); citado por Óscar Hernández Salgar, "La semiótica musical como herramienta para el estudio social de la música", Cuadernos de Música, Artes visuales y Artes escénicas, 7/1 (2012), p. 54. confrontación, una resistencia que el compositor habrá de vencer para posibilitar una nueva forma de escucha, evitando la simple reproducción de lo dado. En el tercer apartado se mostrarán algunos ejemplos de dicho trabajo. Antes de adentrarnos en ello, empero, debemos contextualizar la discusión teórica conducida hasta aquí en el marco general de la poética de Torá.

\section{ASPECTOS GENERALES DE LA POÉTICA DE TORÁ}

\subsection{Concepción del arte y dimensión ético-política de la creación}

Durante una clase celebrada el 2 de abril de 2016 en el Centro Superior Katharina Gurska de Madrid (CSKG), Torá subrayaba la capacidad del arte para hacer escuchar el mundo de forma distinta. Con esto no se refería a la introducción de mensajes ocultos o a estrategias de manipulación emocional, sino a la transformación de la experiencia del sonido basada en su materialidad y sensorialidad y por medio de una contextualización musical que posibilite el extrañamiento de lo familiar. En esta mutación perceptiva reside para Torá el "aspecto subversivo y político del arte”. En este punto, el autor entronca con Benjamin, Adorno y Lachenmann. Así, según Benjamin, el arte está llamado a cambiar la historia. Esto, sin embargo, no consiste en mentir sobre los hechos, sino en "redimirlos". Pero no se trata de un "mesianismo fuerte", sino de escuchar y otorgar la voz a aquellas gargantas que han sido silenciadas.

El pasado porta un secreto índice, a través del cual se remite a la redención. ¿No nos roza acaso un mismo aliento que envolvía a los que otrora fueron? ¿No habita en las voces a las que prestamos oído un eco de los ya silenciados? [...] Así pues, a nosotros nos ha sido concedida una débil fuerza mesiánica, sobre la que el pasado extiende sus derechos. ${ }^{51}$

${ }^{51}$ Benjamin, "Über dem Begriff der Geschichte", en Gesammelte Schriften 1/2 (Frankfurt am Main: Suhrkamp, 1974), pp. 693-694. "Die Vergangenheit führt einen heimlichen Index mit, durch den sie auf die Erlösung verwiesen wird. Streift denn nicht uns selber ein Hauch der Luft, die um die Früheren gewesen ist? Ist nicht in Stimmen, denen wir unser Ohr schenken, ein Echo von nun verstummten? [...] Dann ist uns eine schwache messianische Kraft mitgegeben, an welche die Vergangenheit Anspruch hat". 
También Adorno reconocía en el arte una íntima relación con lo social, atribuyéndole un "aguijón" que ha de entenderse, según Wellmer, como una capacidad para romper y cuestionar clichés perceptivos, abriendo nuevas posibilidades experienciales. ${ }^{52}$ Mediante ese aguijón, el arte se encuentra llamado a hendir la ideología oculta en las obras: el "espíritu sedimentado" que reposa sobre los materiales artísticos. Al permitirle atacar formas congeladas de pensar y percibir, el aguijón habilita al arte a ejercer su crítica sobre la sociedad y redimir el pasado. No obstante, la ruptura de ese "espíritu" conllevaría también una pérdida de carácter lingüístico [delingualisation], en la medida que abandonan los carriles comunicativos de un "lenguaje" artístico establecido. Este abandono consiste para Adorno en una "renuncia" que combina negatividad interna y potencial crítico, entendiendo este como oposición a las concepciones establecidas del arte y a las tendencias a neutralizarlo a través de la industria cultural. "Neutralizar", en términos adornianos, significa despojar al arte de su aguijón, tornándolo mera mercancía u objeto de entretenimiento..$^{53}$

Más adelante, Lachenmann revisita algunas de estas ideas. El músico alemán define el arte como "una forma de magia quebrada y con espíritu, rota en nombre de una voluntad creadora [...] gradualmente más consciente de su fin autónomo" ${ }^{54}$ Esta noción de "magia quebrada" se relaciona con su idea de belleza como "negación del hábito", que, según De Assis, habría tomado de Herbert Marcuse. Además, los lazos con la estética de György Lukács se manifiestan en una visión de lo artístico como lugar en el que la potencialidad inmanente de lo estético se enfrenta a la realidad..$^{55}$ Así, para Lachenmann, el arte solo es arte auténtico si purga de sí mismo lo ideológico, lo que ha degenerado en "idilio". Esta crítica tendría el poder de transformar el arte del pasado. ${ }^{56}$

La dimensión social de la teoría lachenmanniana, explica Wellmer, se plasma en su resistencia ante la trivialización del arte como medio para la reproducción social. Pero la música solo puede ser socialmente significativa desde su autenticidad y, si su factura solo confirma las pre-

52 Wellmer, "On Music and Language”, p. 125.

53 Wellmer, “On Music and Language”, pp. 120, 124-125.

54 Lachenmann, "Philosophy of Composition", p. 55: "[Art is] a form of magic broken (gebrochene Magie) in and with spirit, broken in the name of a creative will that is increasingly realising its autonomous purpose $[\ldots]$ ".

55 De Assis, "The conditions of creation", p. 3.

${ }^{56}$ Wellmer, "On Music and Language”, p. 121. concepciones estéticas, fracasará. ${ }^{57}$ En este sentido se posiciona en contra de la noción de "arte comprometido":

el sentido del arte es para mí el de una forma de aventura, de liberación de los impulsos con la esperanza de realizarme y conocerme mejor a través de la búsqueda. Las demandas de que el arte ofrezca proclamas, instrucción o educación me producen alergia [...] odio al Mesías y amo a Don Quijote [...] y creo en la pequeña cerillera. ${ }^{58}$

En este punto, Wellmer concuerda con Lachenmann: el arte revela el mundo en la medida que abre nuevas posibilidades perceptivas y articula un impulso para trascender la negatividad social. Pero ello no equivale a emitir mensajes críticos sobre un mundo malvado, pues la obra de arte no es un mensaje; su potencial crítico estriba en su capacidad de abrirnos los sentidos y movernos a la reflexión, ayudándonos a descubrir los posos ideológicos. La apertura al mundo es inseparable de la innovación artística; así aparece la verdad en el arte..$^{59}$

Afín a estos planteamientos se sitúa asimismo Mathias Spahlinger, quien, por un lado, subraya la dependencia de la música respecto de los condicionantes de la realidad material, como su reflejo; y, por otro lado, encuentra en esta misma condición de productora de imágenes el fundamento de la capacidad de la música para actuar sobre dicha realidad ${ }^{60}$ Según Alberto Bernal, Spahlinger trata por esta vía de distanciarse tanto de una comprensión apolítica de la músi-

57 Véase Wellmer, “On Music and Language”, pp. 117.

58 Lachenmann, Musik als existentielle Erfahrung, p. 201: "Der Sinn der Kunst sei für mich eine abenteuerliche Form der Triebbefriedigung mit der Erwartung, mich so zu verwirklichen und im Suchen besser zu erkennen. Verkündigungs-, Lehr- und Erziehungs- ansprüche an die Kunst machen mich allergisch [...] Ich hasse den Messias und liebe den Don Quichotte [...] und ich glaube an das kleine Mädchen mit den Schwefelhölzchen”.

59 Lachenmann, Musik als existentielle Erfahrung, p. 126127. Es innegable la huella adorniana en esta concepción. Véase por ejemplo Theodor Adorno, Teoría estética (Madrid: Akal, 2004), pp. 371-372: "lo social en el arte es su movimiento inmanente contra la sociedad, no su toma de posición manifiesta [...] si se puede atribuir a las obras de arte una función social, es su falta de función. Las obras de arte encarnan negativamente mediante su diferencia respecto a la realidad embrujada un estado en el que lo existente ocupa el lugar correcto, su propio lugar. Su encantamiento es desencantamiento".

${ }^{60}$ Véase Spahlinger, "Realidad de la conciencia y realidad para la conciencia", p. 1. 
ca como de una visión apoyada en exclusiva en su posicionamiento externo. De este modo, es justo su configuración interna la que, como "lugar de sedimentación de realidades sociopolíticas", acarrea consigo, al mismo tiempo, la necesidad y la posibilidad de un trabajo crítico, "negativo" por parte del compositor. ${ }^{61}$ De este modo, escribe Spahlinger:

La música auténtica es aquella que mantiene un comportamiento negativo con respecto a sí misma, ya sea al reflejarse en sí misma, o bien al constituirse en negación concreta de sus convenciones. [...] Solamente aquella revolución que también convulsione a la propia música podrá darse en la realidad. ${ }^{62}$

Otro de los referentes principales de Torá es, como se ha mencionado, la poesía de Paul Celan. En ella palpita una angustiosa conciencia sobre la imposibilidad de hablar, como un eco de la célebre sentencia de Adorno: "escribir un poema después de Auschwitz es un acto de barbarie". La época post-Holocausto es, dice Torá, un tiempo de miseria, que vive bajo la sombra aún caliente de "lo indecible, lo no testimoniable". El arte adquiere conciencia de haber sido incapaz de evitar el horror ("la armonía de lo poético asonaba con lo más espantoso"), cuando no su mismo cómplice. ${ }^{63}$ Ante esta situación, ¿qué debe hacer el artista? ¿Debe actuar como si nada hubiera sucedido? El silencio conforma un elemento esencial en la poesía de Celan. Pero este callar no consiste en "no decir nada", sino en un silencio activo ante lo inexpresable, la renuncia a la representación o "estetización" del horror, sobre la que advierte Sagrario Aznar. ${ }^{64}$ Podemos vislumbrar aquí también, quizás, la "angustia de la escritura" de la que habla Derrida, cuando este señala que "hablar me da miedo porque, sin decir nunca bastante, digo también siempre demasiado". ${ }^{5}$

La idea del silencio en Celan tendrá consecuencias profundas en la música de Torá, a través de una búsqueda de autodesaparición, como esfuerzo por dejar hablar al so-

${ }^{61}$ Spahlinger, "Realidad de la conciencia y realidad para la conciencia", nota 17.

62 Spahlinger, "Realidad de la conciencia y realidad para la conciencia", p. 3.

${ }^{63}$ Expresado por Torá durante unas clases celebradas en el CSKG los días 2 y 3 de abril de 2016.

${ }^{64}$ En Aurora Fernández Polanco, Sagrario Aznar Almazán (coord..) y Jesús López Díaz, Prácticas artísticas contemporáneas (Madrid: Ramón Areces, 2015), p. 139.

65 Jacques Derrida, La escritura y la diferencia (Barcelona: Anthropos, 1989), p. 18. nido. En expresiones de Torá, queda reflejado: en el "quehacer del tacto como desprenderse de la mirada"; ${ }^{66}$ en el destruir "lo realizado, volviendo al comienzo, forzando la percepción de este mundo; siempre con un sentimiento de fracaso"; 67 en el deseo de "ver un paisaje tal como es cuando yo no estoy" ["Voir un paysage tel qu'il est quand je n'y suis pas"] de Simone Weil; ${ }^{68}$ en el célebre "¿qué importa quién habla?" [“Qu'importe qui parle?'] de Samuel Beckett: ${ }^{69}$ y en el "más de uno, como yo sin duda, escriben para perder el rostro" de Michel Foucault ["Plus d'un, comme moi sans doute, écrivent pour n' avoir plus de visage"].$^{70} \mathrm{En}$ todas estas actitudes descubre Torá un afán de desaparecer, de hacer desaparecer la voz y el ego, para alcanzar, a través de ello, la plena asunción del mundo y de su historia.

De este modo, explica Torá, el camino conduce al intento de "volver a cantar, pero de una forma nueva, no retrógrada" ${ }^{71}$ Una tentativa, como en Hoffmannsthal, de "leer lo que nunca fue escrito" ["Was nie geschrieben wurde, lesen"], ${ }^{72}$ de encontrar en las páginas de la historia algo que no fue dicho. Esta idea de "volver a cantar", de un "canto nuevo", se ubica en el pensamiento de Torá desde los comienzos de su trayectoria, y ya entonces relacionada con Celan: "y en este espacio recortado, vigilado, buscar la posibilidad del canto, de un otro canto quizá".73

\subsection{El devenir-música de lo no-musical. La idea de traducción}

La obra de Torá refleja un amplio abanico de intereses intelectuales. En cada pieza se establece toda una red

${ }^{66}$ Torá, Notas a "in der bruchlosen Ferne, dans le crevasse du temps" (2001).

${ }^{67}$ Torá, Notas a "d'un trait qui figure et défigure” (2002).

${ }_{68}$ Mencionado por Torá durante el transcurso de las mencionadas clases de los días 2 y 3 de abril de 2016. La cita puede encontrarse en Simone Weil, La pesanteur et la grâce (París: Librairie Plon, 1988), p. 53.

69 Torá, Notas a "quehacer del tacto full of mirroredness" (2009).

70 Torá, Notas a "quehacer del tacto full of mirroredness" (2009).

${ }^{71}$ Durante las citadas clases de los días 2 y 3 de abril de 2016 en el CSKG.

${ }^{72}$ La cita, mencionada en las clases de Torá, puede encontrarse en Hugo von Hoffmannsthal, Der Tod und der Tor (Leipzig: Insel-Verlag, 1906), p. 44.

73 Torá, Notas a "Kaspar Hauser Lied" (1993). 
de referencias, imágenes y conceptos, si bien siempre centrados en torno al sonido. Sin embargo, no cabe hablar nunca de un "programa", en el sentido convencional del término. En la música de Torá encontramos una dimensión poética que es irreductible a lo técnico, pero que se aleja, al mismo tiempo, de toda representación. Esto último puede explicarse del siguiente modo: si la música tratase de representar una realidad, falsificaría dicha realidad y se alienaría a sí misma. Al representar, yo me presento como el otro, cuya voz desaparece en mi representación, mientras que yo mismo no aparezco como tal, sino oculto tras mi pretensión de actuar en lugar del otro. Esto es, entonces, lo contrario de "dejar hablar" al otro: se le impone una voz que no es la suya.

En Torá, en cambio, los modelos no-musicales son puntos de partida, pero no intervienen directamente en el proceso de escritura: el autor extrae de ellos ideas que utilizará para producir un modelo propiamente musical - es decir, ligado al trabajo del material sonoro-. De esta forma, el modelo deviene-musical. Así, cuando, en wq.132 à creux perdu (2017), Torá dice aplicar la técnica del "vaciado del natural" "74 a la Sonata para flauta Wq.132 de C.P.E. Bach, no se trata de una simple metáfora: primero, el compositor interpreta la técnica escultórica como un proceso de copia en el que se emplea un molde en negativo del original, el cual desaparecerá en el proceso final. Después, traslada esto al trabajo compositivo con el instrumento:

pero esta vez no utilizando un molde de yeso [...] ahora utilizando en su lugar [...] el cuerpo físico, frío, formado acústica e históricamente, del saxofón tenor [...] permitiendo que lo orgánico del sonido de la sonata Wq.132, junto con su respiración, su aire, dejen en él rastro y huella: a través de los intersticios, como filtros en negativo (las llaves en cada digitación, la boca del intérprete), abriéndose y cerrándose en el cuerpo sonoro. ${ }^{75}$

74 Véase Torá, Notas a "wq.132 à creux perdu” (2017). Se trata de una técnica escultórica "por medio de la cual se obtiene [...] una copia tridimensional precisa [...] de cualquier elemento de la naturaleza". El à creux perdu es una variante de la misma, en la que el molde "se obtiene de un modelo que se destruirá durante su extracción del molde, quedando tan solo este como «hu-eco perdido»".

${ }^{75}$ Notas a "wq.132 à creux perdu" (2017). La explicación de Torá resulta muy elocuente. Lo que se copia son tres fragmentos de la sonata. El saxofón (en comunión con su intérprete) adopta el papel del yeso. En cuanto a la pieza, no será otra cosa
Para describir el proceso de copia de la sonata de C.P.E Bach, Torá introduce el término "traducción". Este, un concepto clave en la poética toraniana, no designa "un mero trasvase de sentido, sino [...] el encuentro de un objeto situado entre dos lenguas y entre dos autores, produciendo la apertura de un espacio lingüístico en la lengua receptora". Aquí Torá sigue a Benjamin al decir que el original puede no solo permitir, sino también "requerir", una traducción. La traducción posee, pues, una dimensión creativa cuya especificidad no es nunca anticipable: "una traducción, parafraseando a Hoffmansthal, lee lo que no está dicho, pero en otro lenguaje que puede decirlo" ${ }^{76}$

En la traducción se da, pues, una transformación de un espacio lingüístico a otro. Pero ambos apuntan, además, a algo situado más allá de ellos (como el "lenguaje puro" de Benjamin) o, desde nuestra propia visión, entre ambos. Tal "entre" no es una realidad trascendente, sino que corresponde a lo que Wellmer denomina "intermedialidad latente": una "traducibilidad virtual" de los medios, actualizable a través de la creación. ${ }^{77} \mathrm{El}$ resultado es la carencia de "un método fijo y universal de traducción", o de "una verdad única y objetiva del texto literario: en su supervivencia el original se modifica" ${ }^{78}$

que el molde creado a partir del yeso sobre el modelo, y no la copia en "positivo" del resultado final, ya que, como señala el compositor, esta no sería sino una "transcripción" para saxofón de los pasajes citados.

${ }^{76}$ Explicado durante el desarrollo de una clase celebrada el 19 de diciembre de 2015. Véase también Benjamin, "La tarea del traductor", en Teorías de la traducción: antología de textos, coord. Dámaso López García (Cuenca: Universidad de Castilla-La Mancha, 1996), pp. 335-347, p. 336.

77 Véase Wellmer, "On Music and Language". Wellmer acuña en este texto la noción de "relacionalidad-al-mundo" [Weltbezug] como capacidad de un medio para dirigirse a la realidad. Esta se asocia con la verbalidad, pero también se encuentra en la expresión musical, visual y coreográfica. Los medios artísticos se encuentran "conectados en el lenguaje" en función de una "intermedialidad latente" que permite que la música, no siendo un lenguaje, sea en cierto modo "semejante a un lenguaje" (sprachähnlich]). En la pieza de Torá, el paso de la técnica escultórica a una musical se realizaría a través del potencial intermedial del propio concepto de à creux perdu.

${ }^{78}$ Explicado durante el desarrollo de una clase celebrada el 19 de diciembre de 2015. Además, añade Torá, el traductor debe decidir en cada caso primar la materialidad de la palabra o el sentido; aquí el compositor está aludiendo al Prólogo de Fray Luis de León a su traducción del Cantar de los cantares. 
La traducción se entiende, por lo tanto, como una meta-técnica. El compositor distingue en su discurso dos posibilidades básicas: traducción de sonidos (entre medios musicales distintos) y traducción de obras o fragmentos. Sin embargo, a la luz de lo expuesto, creemos justificado añadir un tercer tipo: traducción de modelos no-musicales. De esto último es ejemplo el devenir-musical del vaciado del natural.

\subsection{Sobre la autodesaparición: autolimitación y mediación constructiva}

Hemos visto que la estética toraniana se dirige hacia una desaparición del rostro, de la mano y de la voz, y que el sentido de ello es el de dejar que hable el sonido, callar para que el otro hable. ${ }^{79}$ Torá sigue así a toda una tradición de pensadores que, como Barthes y Foucault, han sometido a crítica la idea moderna del autor. Su crítica se orienta en especial hacia la idea romántica del genio, que sustituye por la visión premoderna de un sujeto habitado por distintos espíritus. De este modo, Torá se aproxima también a la noción posmoderna de un sujeto-texto en el que diferentes hilos se entrelazan, en la que el autor, alejándose de su condición demiúrgica, está llamado a desaparecer bajo la piel del texto.

Esta búsqueda de autodesaparición, a priori, parece entrar en contradicción con el alto grado de minuciosidad y control que caracteriza sus partituras. Es decir, Torá se sitúa en las antípodas de la indeterminación. ¿Cómo, entonces, cabe hablar de autodesaparición? Durante un coloquio el 7 de marzo de 2018, Torá precisaba que el resultado de una pieza no está “abierto", pero sí vinculado a la particularidad del instrumento-intérprete. No existe, pues, la pretensión de que toda ejecución sea idéntica, sino que lo que debe surgir es el resultado particular para esa pareja instrumento-intérprete. Además, Torá defendía que "el control absoluto es justo la mejor manera de desaparecer, ya que, al final, gobierna el propio sonido". Para nuestro autor, la indeterminación no conforma una cesión de la voz, sino, más bien, la dejación de responsabilidad por parte del creador.

Sin embargo, tampoco sería un camino válido una determinación que delegue las decisiones compositivas a un sistema (como hacía, en cierto modo, el serialismo). Torá, entonces, adoptará otra postura, la "autolimitación":

79 Torá, Notas a "quehacer del tacto full of mirroredness" (2009). reducir las posibilidades de movimiento, definir las estrategias de acceso y explorar los intersticios de ese espacio reducido. Esto le permitiría realizar un trabajo exhaustivo con el material y, en la medida en que la limitación le lleve a escuchar sus pliegues más recónditos, el compositor cederá su voz al sonido sin resignarse a la inactividad.

La autolimitación se despliega en la creación a través de los procedimientos de organización del material; encontramos aquí la herencia de la vanguardia. La pretensión "objetivista" del serialismo suponía para Lachenmann una superstición, una concepción descarnada del sonido. Pero no por ello sus métodos carecían de valor; para él mismo, la música es magia mediada "estructuralmente". Y en Torá, la mediación constructiva entre compositor y material, como parte de las estrategias de autolimitación, se revelan como un elemento indispensable en su intento de "desaparecer".

Un estudio en detalle de los recursos de mediación constructiva empleados por Torá excede el marco de este trabajo. No obstante, citaremos tres de los más relevantes. En primer lugar, encontramos en su obra el concepto de "espejo". Por un lado, este se concibe como elemento de replicación o variación ("deformación, acumulación, transformación"). Por otro lado, el espejo sirve como principio de autogeneración, ligado a una "búsqueda de anulación de la «mano»" ${ }^{80}$ En segundo lugar, encontramos planteamientos relacionados con estructuras poéticas, como la forma estrófica provenzal coblas unissonants en la pieza comment subdiviser les regards (6 coblas unissonans) (2006). Aquí, como indica Torá en sus notas a la pieza, la estructura poética se convertiría en "figura arquitectónica para la composición". Finalmente, encontramos el interés de Torá hacia la retórica musical. Podemos decir que el estatus disciplinar de esta es ambiguo, en la medida en que constituye un ejemplo claro de realidad intermedial. Al margen de sus orígenes históricos no-musicales, "retórica musical" no es una metáfora, sino que posee un sentido musical autónomo; lo retórico se sitúa, en cierto modo, entre la música y el lenguaje verbal. De hecho, como subrayaba Torá, "el concepto de «forma musical» es muy posterior a los conceptos de retórica musical". ${ }^{81}$ Así, en el uso de figuras retóricas debe

${ }^{80}$ Torá, Notas a "quehacer del tacto full of mirroredness" (2009).

${ }^{81}$ Durante una clase celebrada en el CSKG en 2016, en una fecha que lamentablemente no fue anotada. 
verse la reinterpretación de una tradición musical en un contexto creativo distinto, más que una traducción de modelos no-musicales como tal.

La retórica conforma un importante elemento organizativo en la obra de este compositor, manifestándose principalmente en dos clases de fenómenos que, en el fondo, constituyen dos caras de una misma moneda. El primero lo podemos relacionar con la teoría de los tópicos musicales, uno de cuyos ejemplos más relevantes es quizás la utilización recurrente del pianto o motivo de segunda menor descendente ${ }^{82}$ a veces se transforma en descenso microtonal y con frecuencia expandido a entidades formales más amplias (melódicas o no), que Torá expresa como una idea general de "caída" ${ }^{83} \mathrm{Y}$ un segundo fenómeno que podríamos identificar con el empleo, a nivel formal, de diversas figuras retóricas como la aposiopesis - entendida como truncamiento o suspensión del gesto ("callar y volver a empezar"),$-{ }^{84}$ o la anadiplosis, en cuanto repetición del material final de un gesto al comienzo del siguiente..$^{85}$

\section{DE LO POÉTICO A LO POYÉTICO: EL TRABAJO CON EL INSTRUMENTO EN EL PROCESO CREATIVO}

A la hora de afrontar la escritura de una nueva obra, Torá trabaja directamente con el instrumento. Como es lógico, el compositor no es un intérprete avezado de cada uno de los instrumentos para los que escribe, pero también, por el mismo motivo, su "tacto" se encuentra menos condicionado que los dedos diestros de un instrumentista veterano. Aprovechando esta circunstancia, Torá trata siempre de desarrollar una técnica personal a través de la exploración

${ }^{82}$ Hernández Salgar, "La semiótica musical como herramienta para el estudio social de la música”, pp. 53-54.

${ }^{83}$ Un ejemplo de "traducción" no melódica de este concepto de "caída" se encontraría, en este sentido, en la sucesión 4-3-21-3-2-1-2-1, que aparece en diversas obras de Torá (como quehacer del tacto full of mirroredness) y se aplica a aspectos como la proporcionalidad formal.

${ }^{84}$ Expresado durante una clase celebrada en el CSKG en 2016, fecha desconocida.

${ }^{85}$ Podría trazarse un cierto paralelismo entre los dos casos mencionados y la distinción que hace Kofi Agawu entre "extroversive semiosis" e "introversive semiosis"; véase Nicholas McKay, "On topics today", Zeitschrift der Gesellschaft für Musiktheorie, 4/1-2 (2007), pp. 165-167. física del instrumento. Por supuesto, eso no impide que tras este acercamiento se logre un conocimiento profundo de las cualidades acústicas del instrumento y de su historia. Así, su labor con el instrumento aspira a la de un palpar consciente que persiga la lectura de lo no-escrito, mediada por la autodesaparición y orientada a un propósito artístico, es decir, a la de una "cartografía" del "tacto".

Ofrecemos a continuación dos ejemplos de este trabajo a través del acercamiento a la obra de Torá. Mucho más cabría decir sobre estas piezas y, desde luego, habría que tomar otras en consideración en la medida en que aspiremos a una visión de conjunto de la producción del autor. No obstante, dado el carácter introductorio de este texto, hemos optado por adecuar nuestra selección de repertorio a su idoneidad para la ilustración de algunos de los aspectos más fundamentales de la poética del instrumento de Torá, incluso si ello puede dar lugar a un cierto sesgo en relación con las fechas relativamente tempranas de ambas composiciones.

\subsection{La autolimitación como vía de apertura en Kaspar Hauser Lied (1993)}

Kaspar Hauser Lied (1993) para piccolo es la primera obra del catálogo de Torá, previa a su estancia formativa en Alemania, y en ella se manifiesta ya de forma clara la idea de autolimitación. Al comienzo de la partitura, Torá presenta cinco posiciones de multifónicos que proporcionan el punto de partida para la pieza. Cada posición se asocia a una digitación concreta de la mano derecha, mientras la izquierda permanece invariable (véase Figura 1).

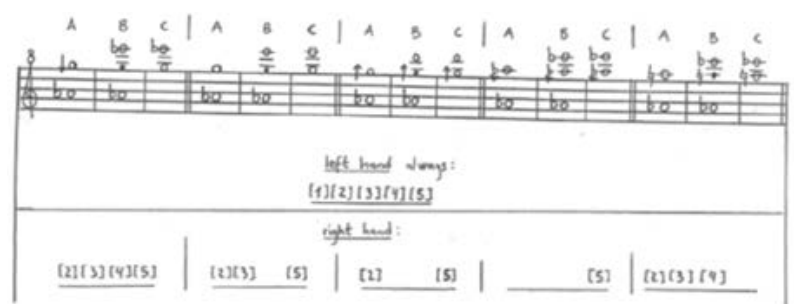

Figura 1. Esquema de multifónicos

de Kaspar Hauser Lied (1993) de Torá en las instrucciones de esta partitura para flautín. ${ }^{86}$

${ }^{86}$ La reproducción de fragmentos de partituras de José Luis Torá (accesibles a través de su portal web https://joseluistora. com) cuenta con su expresa autorización personal. 


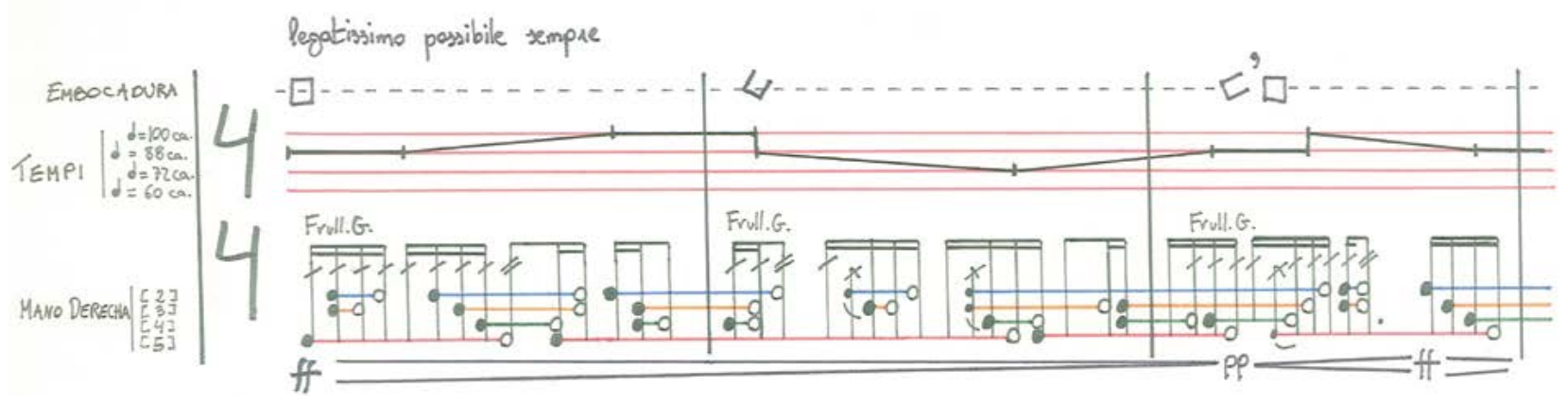

Ejemplo 1. Compases 1-3 de Kaspar Hauser Lied (1993) para flautín de Torá.

Nótese que hemos hablado de "posiciones de multifónicos" y no de multifónicos. Esto significa que aquéllas definen un espacio de posibilidades de acción, no que los sonidos de la obra se reduzcan a cinco "valores" - como si no hubiéramos hecho más que reemplazar las notas tradicionales por multifónicos-. En cambio, Torá trata de explorar cada recoveco de ese espacio limitado, esto es, las posibilidades sonoras que permiten las posiciones al ser conjugadas con las variaciones en diversos aspectos de la producción de sonido, como la velocidad de cambios de digitación, la dinámica, la embocadura y la existencia o no de frullato. De ello dependen las tres variantes de multifónicos que se asignan a cada posición (designadas con las letras A, B y C), así como una amplia gama de relaciones acústicas que habitan los huecos de estos quince pilares. ${ }^{87}$

En el Ejemplo 1 reproducimos los compases iniciales de Kaspar Hauser Lied (1993). Obsérvese cómo está escrita la parte del flautín. En la parte inferior de cada sistema se indican las digitaciones, para lo que Torá sustituye el pentagrama por cuatro líneas que corresponden a los dedos 2-5 de la mano derecha (los únicos que se mueven); las cabezas negras, seguidas de una línea (coloreada en el original), prescriben una llave presionada y mantenida; las cabezas blancas, que interrumpen el dibujo de esta línea, señalan la apertura de la llave. En el mismo lugar se detalla también el ritmo de cambio de las digitaciones, la existencia o no de frullato (" $\mathrm{G}$ " denota frullato de garganta, frente a "L", frullato de lengua) y la dinámica.

${ }^{87}$ En base a la explicación de Torá, la diferencia en la producción de los multifónicos A y B (para unas determinadas condiciones de embocadura, etc.) es básicamente una diferencia en la dinámica: la variante A aparece en pianissimo, la B en fortissimo, y un crescendo o diminuendo nos conducirá de una a otra.
En la parte intermedia de cada sistema encontramos un tetragrama del que Torá se sirve para indicar los cambios en el tempo: sus cuatro líneas indican cuatro valores para la negra $(66,72,88$ y 100), entre los que el intérprete irá fluctuando de forma constante, siguiendo la línea más gruesa que atraviesa el tetragrama. En la parte superior aparece una línea discontinua que recoge la notación de la embocadura. Esta se desplaza entre tres posiciones (abierta, normal y cerrada), además de los puntos intermedios entre ellas.

De este modo, el autor define un campo de trabajo en el que los movimientos son limitados. ${ }^{88}$ Sin embargo, la intermediación de los diferentes factores técnicos le permitirá cosechar abundancia en la escasez ${ }^{89}$ Cobran sentido entonces sus palabras, cuando este habla (en sus notas a la pieza) de "palpar [...] la interioridad del sonido [...] sus grietas e intersticios". No obstante, la pregunta es ahora de qué forma, en esta autolimitación, reside "su posibilidad de apertura" y de "otro canto". Aunque la respuesta a esta pregunta puede plantearse desde distintas

${ }^{88}$ El planteamiento se inspira en la historia de Kaspar Hauser (¿1812?-1833), enigmático "niño salvaje” que pasó su vida confinado en una celda y a quien el poeta Georg Trakl (18871914) dedicó su poema Kaspar Hauser Lied (1912-1914). Vemos aquí, empero, un claro ejemplo de lo anteriormente expuesto: Torá no trata de "representar" el poema o la trágica figura de Hauser, sino que extrae de todo ello ideas que hace devenir-musicales. El "confinamiento" (transformado en auto-restricción) es sin duda lo más relevante aquí.

89 "Intermediación" no significa lo mismo que "independencia", la cual sólo es posible hasta cierto punto. La propia acústica, nos explicaba Torá en una conversación personal, condiciona la vida del sonido: los diferentes factores o "parámetros" son en realidad interdependientes, y esto debe ser tenido en cuenta por el compositor. 
perspectivas, aquí la enfocaremos desde la poética del instrumento: el tratamiento del piccolo que realiza Torá subvierte su identidad heredada.

Por un lado, en Kaspar Hauser Lied el compositor aplica al instrumento (el flautín) un "microscopio" técnico que permite explorar sus ocultos pliegues: el recorte de posibilidades fuerza al intérprete y al oyente a centrar su percepción en estos elementos mínimos, creando un contexto sonoro en el que su riqueza latente es puesta de relieve. Por otro lado, la intermediación de factores técnicos conduce a que algunos movimientos, como señala el autor, actúen de forma "contradictoria". En este sentido, según observaba la flautista Alessandra Rombolà en el citado coloquio del 7 de marzo de 2018, sus expectativas como intérprete se veían continuamente frustradas cuando, ante una acción de la que esperaba un sonido concreto, Torá interponía otra que lo impedía (obteniéndose algo diferente). En este juego encontramos una forma de "negación del hábito", la cual no se circunscribe, no obstante, a la psicología del intérprete: al bloquear productivamente una conexión transitada, se generan unas condiciones acústicas en las que pueden emerger relaciones sonoras nunca recibidas. Así, la consecución de un "canto nuevo" no pasa por una ampliación de las posibilidades del flautín. Por el contrario, dicho canto se alcanza a través de una extrema auto-limitación - como invitación a mirar dentro del sonido- del instrumento.

\subsection{Traducción y memoria en in der bruchlosen Ferne, dans le crevasse du temps (2001)}

\section{In der bruchlosen Ferne, dans le crevasse du temps} (2001) para flauta, clarinete, percusión, violín y violonchelo constituye un excelente ejemplo de la idea de "traducción" ${ }^{90}$ Hemos visto que la frontera entre espacios "lingüísticos" se entiende como un límite positivo que hace posible la traducción como actividad creadora: una "lejanía sin ruptura" que conlleva la transformación de las realidades lingüísticas al atravesarla. En este caso, son

90 Ya el título de la pieza hace referencia implícita a la traducción al combinar dos versos de poemas diferentes donde el primero de ellos, "in der bruchlosen Ferne" [en la lejanía sin distancia], pertenece a un poema de André du Bouchet ["lointain sans rupture"] traducido por Celan; y el segundo, "dans le crevasse du temps" [en la grieta del tiempo], corresponde a un verso de Celan ["in der Zeitenschrunde"] traducido por Du Bouchet. los propios instrumentos los que, con sus particularidades acústicas e históricas, definen sus propios espacios inalienables.

La traducción se convierte aquí, pues, en "traducción de sonido", una técnica que Torá relaciona con el contrapunto canónico, como él mismo lo explica en sus notas a la pieza: "una misma estructura de diversas formas de aparición y desaparición, de presencia y ausencia del material, «atraviesa» simultánea o sucesivamente los diferentes cuerpos sonoros instrumentales [...]". Así, por un lado, encontramos aquí un material que viaja a través del medio acústico, al igual que un sujeto de fuga se desplaza entre las distintas voces. Por otro lado, dicho material no consiste aquí en un patrón de alturas y duraciones, sino en un "sonido" (y una "producción de sonido"). Al hacer esto, puede decirse, Torá está sometiendo al propio contrapunto a una "pérdida de carácter lingüístico". ${ }^{1}$

Ahora bien, ¿cómo puede un violonchelo "traducir" el sonido de una flauta? En el Ejemplo 2a, el gettato desprovisto de altura definida [tonlos] en el violonchelo parece dialogar con los grupos irregulares de golpes de lengua en la flauta. Luego, ambos desembocan en la aparición de la altura - vinculada respectivamente a la posición del arco y a la presión de la mano izquierda en el violonchelo - y a la apertura o cierre de llaves en la flauta. En el Ejemplo 2b, de manera semejante, las variaciones en la mano izquierda del violín (que dan lugar a intermitentes emergencias de un armónico) se corresponden con las oscilaciones de posición y digitación de la flauta, que también producen emergencias de una altura inestable. Más adelante, la articulación separada de la flauta discurrirá en paralelo a una articulación también separada en el violín, y sobre un esquema dinámico similar. ${ }^{92}$

${ }^{91}$ Estos paralelismos y trasvases de material se producen primordialmente entre la cuerda y el viento, ya simultáneamente, ya de forma diferida. La percusión no interviene en el juego de la traducción y su material no evoluciona de la misma manera que en los otros instrumentos, permaneciendo como eje central que separa ambas familias. A cambio, la percusión resultará fundamental en la articulación formal de la pieza.

92 ¿Por qué entonces el resultado de esta articulación de la flauta es tonlos, mientras que la del violín produce una altura determinada? Por una parte, a causa de lo inalienable de cada medio (la "lengua" se nos muestra como un sistema de diferencias significativas, como en Saussure), un cambio análogo no tiene por qué producir el mismo impacto en cada caso. Por otra parte, como se dijo a propósito de los espejos (¿qué es acaso la 

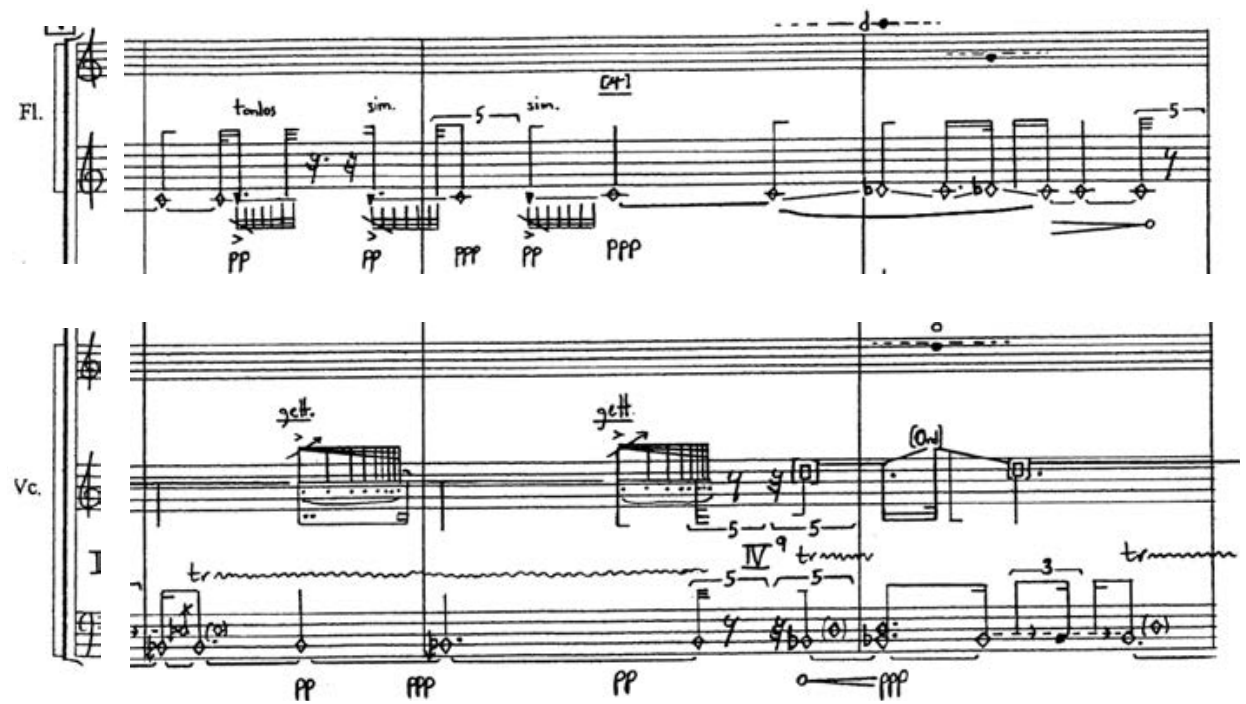

Ejemplo 2a. Detalle de los cc. 5-7 de in der bruchlosen Ferne (2001) de Torá (extrayendo las partes de flauta y violonchelo para compararlas).
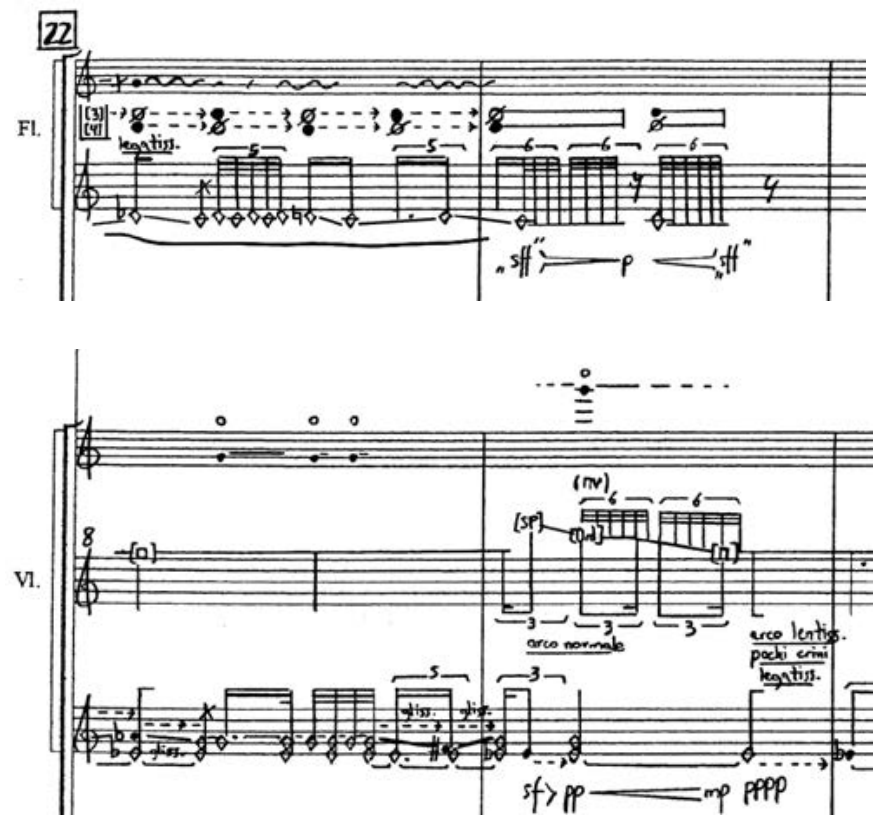

Ejemplo 2b. Detalle de los cc. 22-23 de in der bruchlosen Ferne (2001) de Torá (extrayendo las partes de flauta y violín para compararlas). 
Podemos observar, en estos y otros pasajes de la pieza, elementos técnicos instrumentales con una indudable carga "tonal": el gettato, los armónicos en la cuerda, los trinos, el bariolage, el frullato... todos estos elementos pertenecen a la historia de los instrumentos y forman parte de su idiomatismo, condicionando el acceso del autor a la exploración del potencial acústico latente más allá de la misma. Sin embargo, es la mediación a la que dichos elementos están sometidos la que permite evitar la simple repetición del hábito. En ello la traducción juega un papel importante: al tratar de trasladar a un instrumento determinadas formas de producción sonora propias de otro, se crean en el primero "diferencias" como distanciamiento respecto a su identidad convencional, permitiendo de este modo un extrañamiento de lo familiar.

Ahora bien, ¿cómo es posible producir en primer término esas diferencias? O, en otras palabras, ¿cómo definirlas en la escritura? No debe subestimarse en este punto la importancia de la "notación", en la medida en que esta no es neutra respecto al modelo de sonido que propone. De forma irremediable, la partitura categoriza la acción sonora (a través de "componentes" como altura, duración, dinámica...). Como la lengua para Saussure, aquélla se conforma como un sistema (virtual) de diferencias que cierra y abre al mismo un espacio de posibilidades. La escritura de Torá, en este sentido, establece sus propios ejes de coordenadas, permitiendo definir con precisión transformaciones sutiles en los mecanismos de producción del sonido.

Ilustraremos esto con un ejemplo sencillo, tomado de la parte del violín (Ejemplo 3). Como puede verse, Torá emplea simultáneamente tres pentagramas: en el inferior, se indican las acciones de la mano izquierda (junto a la dinámica); en el central, las de la mano derecha, esto es, la posición del arco sobre la cuerda (que corresponde, en cada caso, al punto de esta que habría que pisar para producir, de forma convencional, la altura especificada); en cuanto al pentagrama superior, de carácter auxiliar, se emplea para señalar - cuando es preciso- la altura de los armónicos que deben emerger en el proceso..$^{93}$

imitación canónica sino la producción de un reflejo?), la replicación no es su única función —al igual que, en el contrapunto clásico, hay distintos mecanismos de imitación-.

${ }_{93}$ De esta manera, la notación de Torá reconfigura la relación que guardan entre sí las diversas acciones simultáneas del intérprete: una independencia de manos que confronta directamente sus hábitos físicos y mentales, requiriendo - en cierto modo - el desarrollo de una técnica distinta.
En el Ejemplo 3, cuando el arco está colocado sobre la posición del $\mathrm{Fa}_{5}$ (siguiendo el sistema franco-belga de notación: $\mathrm{La}_{3}=440 \mathrm{~Hz}$ ), el trino de la mano izquierda no origina el armónico correspondiente (el $\mathrm{Fa}_{5}$ del compás 4), sino que permanece en una indefinición de altura. La altura no surge sino cuando el arco se desplaza hasta su posición ordinaria y el trino deja paso a una posición estable de armónico digitado con dos dedos (sobre dos nodos diferentes del mismo armónico). Después, el armónico desaparecerá al cambiar de nuevo la posición del arco y aumentar la presión de uno de los dedos de la mano izquierda. Así, durante todo este pasaje, la posición de esta mano se mantiene fija, pero los leves cambios en la acción ejecutante tendrán como consecuencia variaciones sonoras significativas. Por consiguiente, la notación se manifiesta también, en este contexto, como un elemento de mediación constructiva: la idea y su representación lingüística no son escindibles, sino que se co-implican y, por tanto, condicionan el acercamiento al instrumento y al sonido. Es tan solo sobre $-\mathrm{y}$ a través de - estas coordenadas como se lleva a cabo el ejercicio de la traducción.

Antes de concluir, queremos referirnos a un interesante fenómeno relacionado con la confrontación del aura instrumental, situado casi al final de in der bruchlosen Ferne (2001) y que habría sido inconcebible - de ese modo, al menos - fuera del contexto musical en el que lo introduce Torá. Pero para comprender esto, y aunque no sea este el lugar para un análisis exhaustivo de la obra, hemos de referirnos antes a su estructura global, siquiera de forma sucinta. Cabe distinguir cuatro secciones en esta obra: la primera sección (cc. 1-66), gobernada por la alternancia entre los sucesivos "reinicios" del material inicial y pequeñas "cuñas" contrastantes, y en la que el tonlos es predominante; la segunda (cc. 67-101), en la que se incorporan nuevos materiales y se produce un vaciamiento de la textura a través del silencio; la tercera (cc. 102126), dotada de mayor linealidad, que conduce al clímax y en la que predomina la altura definida; y la última (cc. 127-162), en la que los diversos materiales retornan de una manera fragmentada y progresivamente descontextualizada. Es en este momento postrero, entre los "escombros" de los materiales sonoros, entre los silencios de un discurso constantemente interrumpido, cuando acontece de un modo súbito y explosivo la "liberación" del sonido de la campana (c. 152), esto es, el estallido desnudo de lo máximamente cargado en un contexto no-familiar, inhóspito y extraviado (véase Ejemplo 4). 


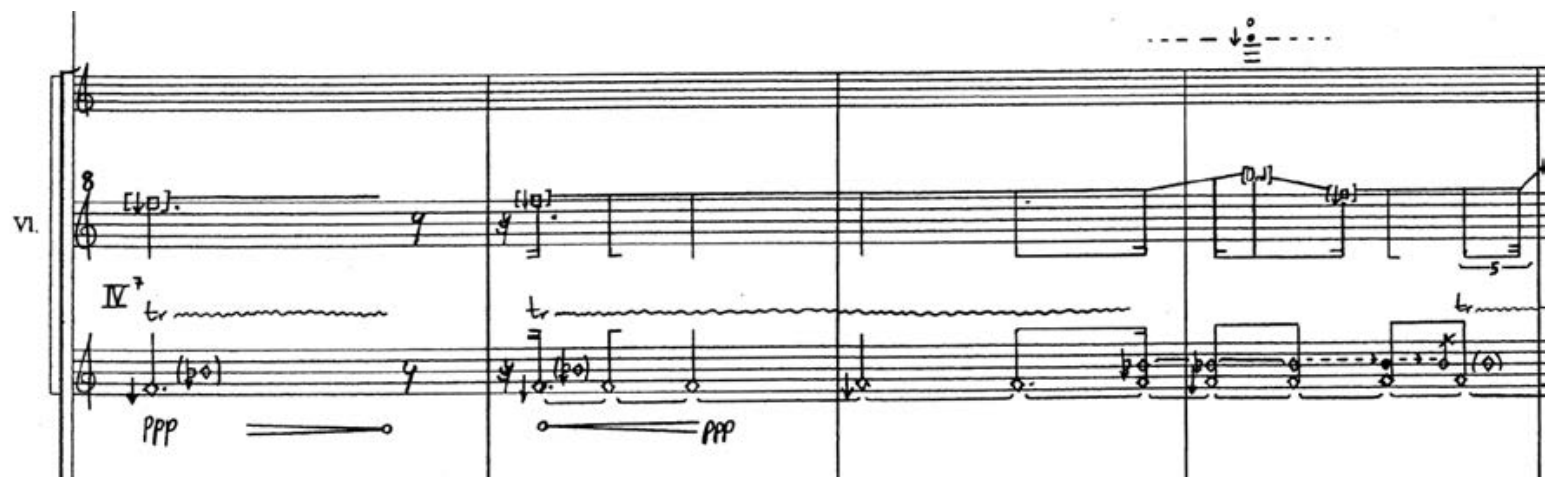

Ejemplo 3. Detalle de los cc. 1-4 (parte de violín) de in der bruchlosen Ferne (2001) de Torá.

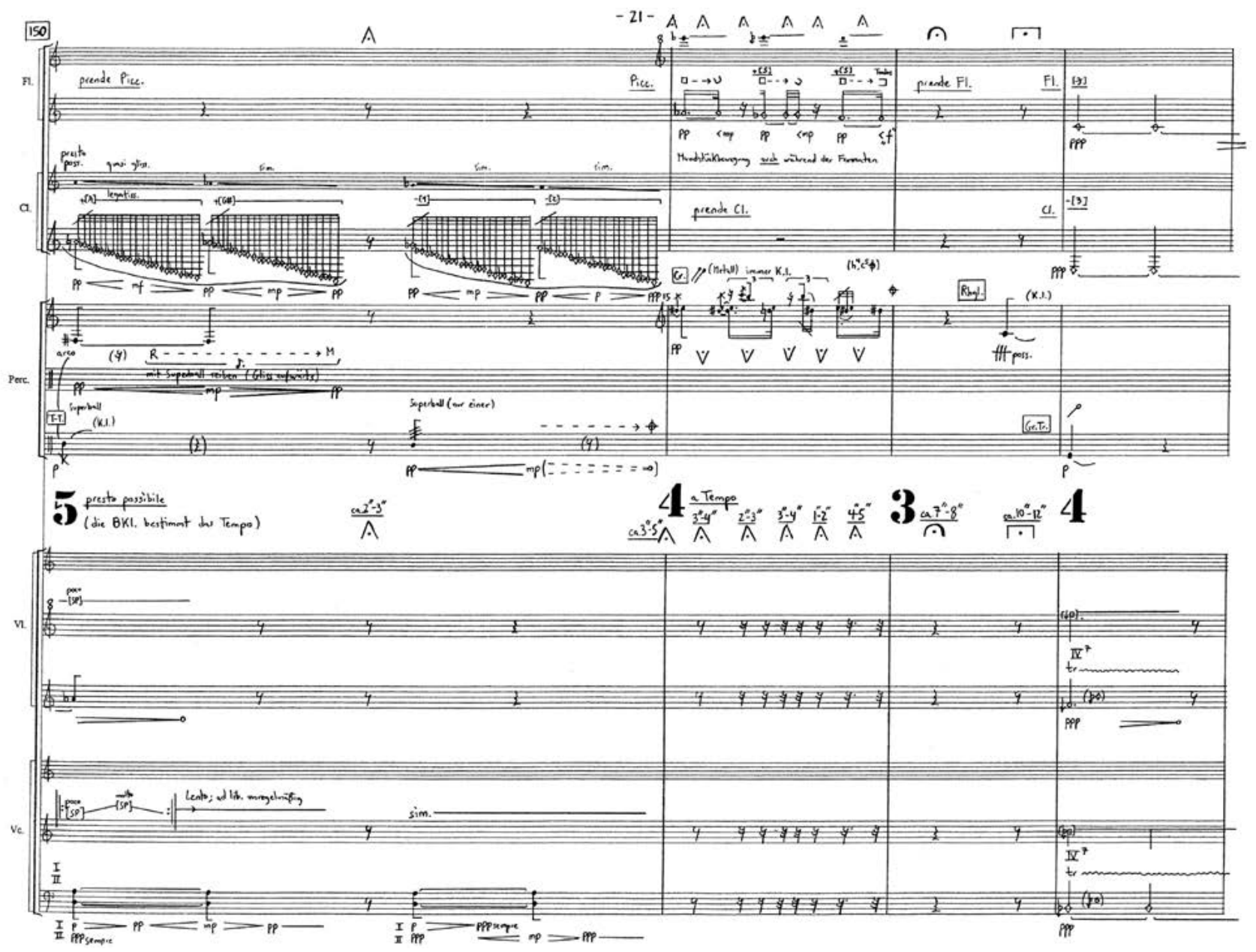

Ejemplo 4. Torá, in der bruchlosen Ferne, cc. 150-153, con la intervención de la campana en el c. 152. 
Podemos interpretar esto de la siguiente forma. A lo largo de la pieza, en el oído y la memoria del oyente se han ido elaborando una serie de relaciones, experiencias perceptivas, "imágenes". ${ }^{44} \mathrm{El}$ potente golpe de la campana rasga en dos, repentinamente, el velo de ese encantamiento. En esa grieta o conflicto que se abre entre dos memorias - la memoria de la escucha en la obra y la memoria que el instrumento porta consigo - , la campana emerge como a caballo entre dos mundos. En ese instante, ella puede escucharse de una manera nueva, extrañamente pura, como si nunca hubiera sido escuchada: ¿es esta la redención benjaminiana?

\section{CONCLUSIONES}

Según se planteó al comienzo de este trabajo, nuestra exploración del pensamiento y la obra de Torá debe poder conducirnos a una representación cartográfica de su poética del instrumento. Sin duda, nuestra aventura no acaba más que comenzar. No obstante, por el momento, a modo de síntesis, podemos intentar una recapitulación provisional a partir de las huellas dejadas en nuestro viaje, así como tratar de identificar algunos de los puntos ciegos que nuestra travesía haya podido olvidar en sus márgenes.

Por lo que respecta a la primera cuestión, podemos subrayar la importancia que en el trabajo toraniano con el instrumento posee su concepción del mismo como un cuerpo sonoro formado históricamente. Por un lado, se reivindica su corporeidad, reconociendo la existencia de relaciones acústicas latentes, llamadas a actualizarse a través del proceso creativo. Por otro lado, se llama la atención sobre la memoria sedimentada en el instrumento como objeto cultural, que media en todo acceso al instrumento y ante el que el compositor trata de adoptar una postura reflexiva y crítica.

Además, ha de destacarse la honda ligazón que, en el intento de someter los hábitos técnicos y perceptivos a un extrañamiento, vincula íntimamente el trabajo con el instrumento con todo un conjunto de procedimientos de mediación constructiva - como una "mediación de la mediación"-, desde la notación como configuración de un espacio virtual y gráfico de diferencias a la "traducción" como meta-técnica de trasvase creativo a través de las fronteras entre medios distintos (instrumentos, obras, ámbitos

94 Torá, Notas a "in der bruchlosen Ferne, dans le crevasse du temps" (2001). artísticos), pasando por el espejo, la retórica y la autolimitación. Todos estos aspectos se integran en un proyecto artístico - con resonancias éticas - de autodesaparición, en cuanto a una actitud de renuncia, de un callar reflexivo, tratando, a través de ellos, de devolver la voz al instrumento, al sonido y a cuanto ha sido silenciado.

Ciertamente, restan todavía muchas líneas por marcar en este mapa. Es posible señalar con justicia que, en esta cartografía, se han privilegiado determinadas conexiones estéticas (Lachenmann, Adorno) en detrimento quizás de otros puntos de referencia, como Brian Ferneyhough, Salvatore Sciarrino o Mauricio Sotelo - también implicados en la formación artística de Torá-, o de otros vínculos posibles con compositores pertenecientes a su misma generación, españoles (como Ramon Lazkano o José María Sánchez-Verdú) o no (como Pierluigi Billone o Marco Stroppa). En este sentido, en la poética toraniana no dejan de estar presentes algunos de los rasgos que Martin Kaltenecker señala como espacios comunes en la "música contemporánea" de las últimas décadas, tales como el interés en el "gesto" y la corporalidad del intérprete, la interdependencia de sonido y forma, y la importancia de la escucha como proceso que "completa" la obra. ${ }^{95}$ Todos estos rastros quedan ahora para futuras investigaciones.

No obstante, este afán musicológico por el descubrimiento de rasgos comunes (tanto de época como generacionales, nacionales y otros) no debería nunca conducirnos a una pérdida de sensibilidad respecto a la diferencia, sino que, por el contrario, habría de permitirnos en todo caso una percepción más profunda de la misma. A este respecto, cuanto se ha visto a lo largo de estas páginas nos muestra que la poética de Torá bebe de diversas fuentes, tanto artísticas como filosóficas, y se deja influir de un modo profundo por ellas. Sin embargo, el compositor procura siempre evitar que sus modelos lo devoren, reinterpretándolos desde un punto de vista personal. Es precisamente esta "distancia sin ruptura" la que debe ser escrutada y calibrada en nuestro viaje, sin negar la distancia, y sin olvidar la unión que en ella late.

\section{BIBLIOGRAFÍA CITADA}

Adorno, Theodor W. Teoría estética, traducción de Jorge Navarro Pérez. Madrid: Akal, 2004.

\footnotetext{
95 Martin Kaltenecker, "Ramon Lazkano's Territories", Contemporary Music Review, 38/1-2 (2019), pp. 137-138.
} 
Barthes, Roland. El susurro del lenguaje. Barcelona: Paidós, 1987.

Benjamin, Walter. Discursos interrumpidos [I]. Buenos Aires: Taurus, 1989.

- "La obra de arte en la época de su reproductibilidad técnica". En Obras [vol. I, libro 2]. Madrid: Abada, 2008, pp. 7-86.

- "Über dem Begriff der Geschichte". En Gesammelte Schriften, 1/2. Frankfurt am Main: Suhrkamp, 1974, pp. 693-704.

__. "La tarea del traductor". En Teorías de la traducción: antología de textos, coord. Dámaso López García. Cuenca: Universidad de Castilla-La Mancha, 1996, pp. 335-347.

Brosin, Annette. "Musical Memory, Cultural Memory, and Digital Technologies: Perspectives and Analytical Approaches". Tesis doctoral, University of Victoria [Canadá], 2015.

Cross, Jonathan. "Writing about Living Composers: Questions, Problems, Contexts". En Jonathan Cross, Jonathan Harvey, Helmut Lachenmann, Albrecht Wellmer y Richard Klein, Identity and Difference. Essays on Music, Language and Time. Collected Writings of the Orpheus Institute. Leuven: Leuven University Press, 2004, pp. 9-42.

De Assis, Paulo. "The conditions of creation and the haecceity of the music material: Philosophical-aesthetic convergences between Helmut Lachenmann and Gilles Deleuze”. Filigrane, 13 (mayo 2011), pp. 1-17.

Deleuze, Gilles y Félix Guattari. Mil mesetas. Capitalismo y esquizofrenia. Valencia: Pre-Textos, 2015.

Derrida, Jacques. La escritura y la diferencia. Barcelona: Anthropos, 1989.

Fernández Polanco, Aurora, Sagrario Aznar Almazán (coord.) y Jesús López Díaz. Prácticas artísticas contemporáneas. Madrid: Editorial Universitaria Ramón Areces, 2015.

Gadamer, Hans G. Verdad y método [I]. Madrid: Trotta, 2012.

Heatlicote, Abigail. Liberating Sounds: Philosophical Perspectives on the Music and Writings of Helmut Lachenmann. Durham: Durham University, 2003.

Heidegger, Martin. Ser y tiempo, traducción de Jorge Eduardo Rivera. Madrid: Trotta, 2012.

- Caminos de bosque, versión española a cargo de Helena Cortés y Arturo Leyte. Madrid: Alianza, 2010.

Hernández Salgar, Óscar. "La semiótica musical como herramienta para el estudio social de la música".
Cuadernos de Música, Artes visuales y Artes escénicas, 7/1 (enero-junio 2012), pp. 39-77.

Hoffmannsthal, Hugo von. Der Tod und der Tor. Leipzig: Insel-Verlag, 1906.

Kaltenecker, Martin. "Ramon Lazkano's Territories". Contemporary Music Review, 38/1-2 (2019), pp. 132-147.

Lachenmann, Helmut. Musik als existentielle Erfahrung, edición a cargo de Josef Häusler. Wiesbaden: Breitopf \& Härtel, 1996.

—. "Philosophy of Composition -Is there such a thing?". En Jonathan Cross, Jonathan Harvey, Helmut Lachenmann, Albrecht Wellmer y Richard Klein, Identity and Difference. Essays on Music, Language and Time. Collected Writings of the Orpheus Institute. Leuven: Leuven University Press, 2004, pp. 55-70.

_. "Cuatro aspectos fundamentales de la escucha musical", traducción de Alberto C. Bernal, sin fecha; consultado el 10 de agosto de 2020 en: http://www. tallersonoro.com/anterioresES/07/Articulo2.htm

López-Cano, Rubén. "Entre el giro lingüístico y el guiño hermenéutico: tópicos y competencia en la semiótica musical actual". Revista Cuicuilco, 9/25 (mayo-agosto 2002); consultado el 21 de agosto de 2020 en: http://rlopezcano.blogspot.com/p/publicaciones-ruben-lopez-cano-1996.html

McKay, Nicholas. "On topics today". Zeitschrift der Gesellschaft für Musiktheorie, 4/1-2 (2007), pp. 159-183.

Merleau-Ponty, Maurice. Fenomenología de la percepción. Buenos Aires: Planeta, 1993.

Neuwirth, Markus. "Strukturell vermittelte Magie. Kognitionswissenschaftliche Annäherung an Helmut Lachenmanns Pression und Allegro Sostenuto". En Musik als Wahrnehmungskunst. Untersuchungen zu Kompositionsmethodik und Hörästhetik bei Helmut Lachenmann, editado por Christian Utz y Clemens Gadenstätter. Saarbrücken: PFAU Verlag, 2008, pp. 73-100.

Pabón, José M. Diccionario bilingüe Griego clásico-Español. Barcelona: Vox, 2017.

Serres, Michael. Variations on the Body. Minneapolis, MN: Univocal, 2011.

Spahlinger, Mathias. "Realidad de la conciencia y realidad para la conciencia. Aspectos políticos de la música", traducción de Alberto C. Bernal, 2007; consultado el 23 de agosto de 2020 en: http://docs. albertobernal.net/bernal_musica-y-realidad-2.html 
Utz, Christian. “«Liberating» Sound and Perception. Historical and Methodological Preconditions of a Morphosyntactic Approach to Post-Tonal Music". En Organized Sound Klang und Wahrnehmung in der Musik des 20. und 21. Jahrhunderts (vol. 6), editado por Christian Utz. Saarbrücken: PFAU Verlag, 2013, pp. 11-46.

- "Entwürfe zu einer Theorie musikalischer Syntax. Morphosyntaktische Beziehungen zwischen Alltagswahrnehmung und dem Hören tonaler und posttonaler Musik". En Musik-Sprachen. Beiträge zur Sprachnähe und Sprachferne von Musik im Dialog mit Albrecht Wellmer, editado por Christian Utz. Saarbrücken: PFAU Verlag, 2013, pp. 61-101.

Weil, Simone. La pesanteur et la grâce. París: Librairie Plon, 1988.

Wellmer, Albrecht. "On Music and Language". En Jonathan Cross, Jonathan Harvey, Helmut Lachenmann, Albrecht Wellmer y Richard Klein, Identity and Difference. Essays on Music, Language and Time. Collected Writings of the Orpheus Institute. Leuven: Leuven University Press, 2004, pp. 71-132.

Wilson, Samuel. "Building an Instrument, Building an Instrumentalist: Helmut Lachenmann's Serynade".
Contemporary Music Review, 32/5 (noviembre 2013), pp. 425-436.

\section{Escritos de José Luis Torá (comentarios a sus piezas)}

Todos los textos de Torá se han recuperado de la página web del autor (https://joseluistora.com). La reproducción de fragmentos de partituras (también accesibles a través de su web) cuenta, asimismo, con su expresa autorización personal.

- Kaspar Hauser Lied (1993).

- de una estela incierta (-Aschenlid) (1996-1997, rev. 1999).

- in der bruchlosen Ferne, dans le crevasse du temps (2001)

- d'un trait qui figure et défigure (2002)

- comment subdiviser les regards (6 coblas unissonans) (2006)

- doppio lume s'addua (figure of grammar) (2007)

- quehacer del tacto full of mirroredness (2009)

- wq.132 à creux perdu (2017)

Recibido: 08.04.2020

Aceptado: 11.08 .2020 